\title{
Tort Liability and Unawareness
}

\author{
Surajeet Chakravarty \\ University of Exeter, s.chakravarty@exeter.ac.uk \\ David Kelsey \\ University of Exeter, d.kelsey@exeter.ac.uk \\ Joshua C. Teitelbaum \\ Georgetown University Law Center, jct48@law.georgetown.edu
}

This paper can be downloaded free of charge from:

https://scholarship.law.georgetown.edu/facpub/2067

https://ssrn.com/abstract=3179753

This open-access article is brought to you by the Georgetown Law Library. Posted with permission of the author. Follow this and additional works at: https://scholarship.law.georgetown.edu/facpub

Part of the Law and Society Commons, and the Torts Commons 


\title{
Tort Liability and Unawareness
}

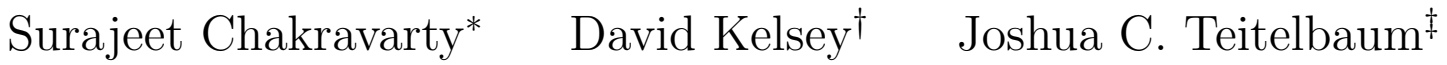

Draft: July 24, 2022

\begin{abstract}
We explore the implications of unawareness for tort law. We study cases where injurers and victims initially are unaware that some acts can yield some consequences, or alternatively that some acts or consequences are even possible, but later become aware. Following Karni and Vierø (2013) we model unawareness by Reverse Bayesianism. We compare the two basic liability rules of Anglo-American tort law, negligence and strict liability, and argue that negligence has an important advantage over strict liability in a world with unawareness - negligence, through the stipulation of due care standards, spreads awareness about the updated probability of harm.
\end{abstract}

Keywords: negligence, Reverse Bayesianism, strict liability, tort law, unawareness. JEL Codes: D83, K13.

*University of Exeter, Department of Economics, S.Chakravarty@exeter.ac.uk.

${ }^{\dagger}$ University of Nottingham, Department of Industrial Economics, David.Kelsey@nottingham.ac.uk.

$\ddagger$ Georgetown University, Law Center, jct48@georgetown.edu. 


\section{Introduction}

Background Expected utility theory (Savage, 1954) posits a space of mutually exclusive and collectively exhaustive states of the world, representing all possible resolutions of uncertainty. It assumes that when a person chooses an act, although she is uncertain about the true state of the world and therefore about the consequences of her chosen act, she nevertheless has complete knowledge of the state space - she knows all the possible acts and all the possible consequences of each and every act. In reality, of course, people often lack complete knowledge of the state space. This is known as unawareness. People may be unaware of some acts, some consequences, or that a known act can yield a known consequence.

Unawareness plays an important role in many economic and legal spheres. A prime example is that people may write incomplete contracts due to unforeseen contingencies. Another example is that a person may be unaware that an act can result in criminal liability. A third example is that a person may not be aware of all the objections that she can raise to a witness's testimony in a trial. In this paper we study the implications of unawareness for tort law, the branch of the common law that governs liability for civil wrongs.

Tort liability rules and unawareness A central question in law and economics is whether negligence or strict liability is the more efficient tort liability rule. Under negligence a victim can recover damages for harm caused by an injurer who failed to take reasonable care. Under strict liability, by contrast, a victim can recover damages for harm caused by the activity of an injurer irrespective of the injurer's level of care. The relative efficiency of the two rules is customarily measured by the Kaldor-Hicks criterion.

A bedrock result in the economic analysis of tort law is that, in the case of unilateral accidents with fixed activity levels, negligence and strict liability are equally efficient, provided that, in the case of negligence, the court properly sets the due care standard (the legal standard for what constitutes reasonable care) (Shavell, 1987). ${ }^{1}$ This equivalence result, however, presents something of a puzzle in light of two facts about negligence. First, negligence is the dominant rule in Anglo-American law. ${ }^{2}$ Second, negligence is the more costly rule to administer, because the court must determine the due care standard and adjudicate

\footnotetext{
${ }^{1}$ In unilateral accidents, the injurer, but not the victim, can take care to reduce expected harm. If the activity level is fixed, the injurer affects expected harm only through her level of care (and not through her level of activity). The equivalence result also holds in the case of bilateral accidents with fixed activity levels, provided that strict liability is coupled with the defense of contributory negligence.

${ }^{2}$ In modern Anglo-American law, strict liability applies only in a handful of accident cases, including cases involving abnormally dangerous activities or products with manufacturing defects (Dobbs et al., 2011,
} 
whether it was met. The puzzle is that if negligence and strict liability are equally efficient but negligence is more costly to administer, why is negligence the dominant rule?

The negligence puzzle has led researchers to revisit the equivalence result by exploring departures from the standard accident model, which is based on the expected utility framework and the Bayesian paradigm. For instance, Teitelbaum (2007) and Chakravarty and Kelsey (2017) explore ambiguity (Knightian uncertainty). They assume the relevant parties have neo-additive preferences and find that this breaks the equivalence in favor of negligence. ${ }^{3}$

We explore unawareness. We study cases where injurers and victims initially are unaware that some acts can yield some consequences, or alternatively that some acts or consequences are even possible, but later become aware. The phenomenon of becoming aware is known as growing awareness. It is the expansion of the state space when a person discovers a new act, consequence, or act-consequence link. Examples relevant to tort law include the discovery of a new product or technology (new act), the discovery of a new disease or injury (new consequence), or the discovery that a known product can cause a known injury (new link).

We explore the implications of unawareness for tort law, and specifically for the negligence versus strict liability debate. To model growing awareness, which requires a theory of how beliefs update as the state space expands, we adopt the Reverse Bayesian approach of Karni and Vierø (2013). Reverse Bayesianism posits that as a person becomes aware of new possibilities, she updates her beliefs in a way that preserves the relative likelihoods of events in the original state space. More specifically, it postulates that (i) in the case of a new act or consequence, probability mass shifts proportionally away from the events in the original state space to the new events in the expanded state space, and (ii) in the case of a new link, null events in the original state space become non-null, and probability mass shifts proportionally away from the original non-null events to these events. ${ }^{4}$

We argue that negligence has an important advantage over strict liability in a world with unawareness. Under either liability rule a tort litigation involving a new act, consequence, or link makes the world aware of a new possibility of harm. Under negligence, however, the litigation provides the world with more information. In particular, the court's stipulation of a

$\S 2)$. Indeed, certain accident cases that were traditionally governed by strict liability are now governed by negligence, including cases involving products with a design or warning defect (Dobbs et al., 2011, § 450).

${ }^{3}$ The neo-additive model was developed by Chateauneuf et al. (2007). Franzoni (2017) models ambiguity according to the smooth model of Klibanoff et al. (2005). He finds that strict liability dominates negligence when the injurer has lower degrees of uncertainty aversion than the victim and can formulate more precise estimates of the probability of harm, but that negligence dominates strict liability when harm is dispersed over a very large number of victims, irrespective of the parties' respective degrees of uncertainty aversion.

${ }^{4} \mathrm{~A}$ null event is an event believed to have zero probability. 
new due care standard serves as a knowledge transmission mechanism, revealing information about the probability of harm. This enables the injurers of the world to take efficient care. Negligence provides this information to injurers. Under strict liability they would have to expend additional resources to develop this information on their own.

McApline v. Bercow Our argument can be illustrated by the landmark Twitter defamation case McAlpine v Bercow. ${ }^{5}$ On November 2, 2012 the BBC broadcast an interview with a man who alleged that as a boy he was sexually abused by an unnamed senior politician in the Thatcher government. Two days later Sally Bercow, a journalist, tweeted "Why is Lord McAlpine trending? *innocent face*." 6 After McAlpine was cleared of suspicion, he sued Bercow for libel, claiming that her tweet implied he was a pedophile who was guilty of sexually abusing boys. The court agreed with McAlpine and held Bercow liable. Following the decision, a legal commentator observed: "The judgment is one of great public interest and provides a warning to and guidance for people who use social media" (Rozenberg, 2013).

Two features of the McApline case are interesting. First, there was unawareness. Sally Bercow defamed Lord McAlpine using a new technology, social media, which is an example of a new act. Second, the court's decision revealed a potential harm of this new act. Future users of social media received useful information about acceptable ways to use it.

Structure of the paper Section 2 introduces the accident model - a unilateral accident model featuring multiple activities with fixed levels - and presents the equivalence result. Section 3 describes the unawareness model. In Section 4 we present relevant examples of tort cases involving unawareness. Section 5 compares and contrasts negligence and strict liability in a world with unawareness. It considers a simple model with two acts, two consequences, quadratic care costs, and linear expected harm reduction, and separately analyzes the cases of a new act, a new consequence, and a new link. Section 6 extends the analysis to a more general model with arbitrary numbers of acts and consequences, convex care costs, and convex expected harm reduction. In Section 7 we relate our results to the existing literature. We offer concluding remarks in Section 8. The Appendix collects the proofs of all results.

\footnotetext{
${ }^{5}$ See [2013] EWHC 1342 (QB).

${ }^{6}$ As a prominent journalist and the wife of the Speaker of the House of Commons, Bercow was well known to the public and had 56,000 followers on Twitter.
} 


\section{The Accident Model}

There are two agents: an injurer and a victim. Both are risk-neutral expected utility maximizers. The agents are strangers and not in a contractual relationship. Transaction costs are sufficiently high to preclude Coasian bargaining.

The injurer has available $m \geq 2$ activities, $f_{1}, \ldots, f_{m}$. Each activity has the potential to cause harm to the victim. We assume that the activities are independent experiments, akin to $m$ one-armed bandits. We refer to this assumption below as Act Independence. ${ }^{7}$

There are $n \geq 2$ potential degrees of harm, $z_{1}, \ldots, z_{n}$, where $z_{j} \geq 0$ for all $j=1, \ldots, n$. Activity $f_{i}$ causes harm $z_{j}$ with probability $\pi_{i j}$, where $\sum_{j=1}^{n} \pi_{i j}=1$ for all $i=1, \ldots, m$. Thus, activity $f_{i}$ 's expected harm is $\sum_{j=1}^{n} \pi_{i j} z_{j}$. In the absence of unawareness, the agents have correct beliefs about each harm probability $\pi_{i j}$.

The injurer engages in each available activity. For each activity $f_{i}$ the injurer, but not the victim, can take care to reduce the expected harm. The injurer chooses a level of care $x_{i} \geq 0$ having cost $c\left(x_{i}\right)$. Being careless is costless, $c(0)=0$, and the marginal cost of care is positive and increasing: $c^{\prime}\left(x_{i}\right)>0$ and $c^{\prime \prime}\left(x_{i}\right)>0$ for all $x_{i}$. Taking care reduces the activity's expected harm at a non-increasing rate: $h_{i}\left(x_{i}\right) \equiv \sum_{j=1}^{n} \pi_{i j} z_{j} \tau\left(x_{i}\right)$, where $\tau\left(x_{i}\right) \in(0,1]$ for all $x_{i}$ with $\tau(0)=1$ and where $\tau^{\prime}\left(x_{i}\right)<0$ and $\tau^{\prime \prime}\left(x_{i}\right) \geq 0$ for all $x_{i}$. Care reduces expected harm by decreasing the probability of harm, the magnitude of harm, or both. We assume that $c(\cdot)$ and $\tau(\cdot)$ are known to all parties and are the same for all activities. We make the latter assumption for simplicity. It is without loss of generality given the former assumption.

If activity $f_{i}$ causes harm, then the victim may be entitled to damages, depending on the applicable tort liability rule. Under negligence the victim is entitled to damages equal to the harm if the injurer's level of care was below the due care standard stipulated by the court. ${ }^{8}$ Under strict liability, by contrast, the victim is entitled to damages equal to the harm irrespective of the injurer's level of care. We assume the injurer has the ability to pay any and all damages to which the victim may be entitled.

\footnotetext{
${ }^{7}$ While Act Independence is a reasonable assumption in many settings, there undoubtedly are settings in which it is not. We explore the implications for our analysis of relaxing Act Independence in Section 5.4. For a thorough treatment of Reserve Bayesianism and Act Independence, see Chakravarty et al. (2022).

${ }^{8}$ Following in the tradition of the tort law and economics literature, we model the due care standard as a precise stipulation. In reality, the due care standard may be less specific. For a discussion on the specificity of the due care standard at common law, see Dobbs et al. (2011, § 145).
} 
The social goal is to minimize the total social costs of the injurer's activities (the sum of the costs of care and the expected harms):

$$
\min _{x_{1}, \ldots, x_{m} \geq 0} \sum_{i=1}^{m} c\left(x_{i}\right)+h_{i}\left(x_{i}\right) .
$$

The solution $\widetilde{x}=\left(\widetilde{x}_{1}, \ldots, \widetilde{x}_{m}\right)$ is given implicitly by the first order conditions $c^{\prime}\left(\widetilde{x}_{i}\right)=-h_{i}^{\prime}\left(\widetilde{x}_{i}\right), i=1, \ldots, m$, and is given explicitly by

$$
\widetilde{x}_{i}=\xi^{-1}\left(\sum_{j=1}^{n} \pi_{i j} z_{j}\right), \quad i=1, \ldots, m
$$

where $\xi^{-1}$ denotes the inverse of $\xi\left(x_{i}\right) \equiv-c^{\prime}\left(x_{i}\right) / \tau^{\prime}\left(x_{i}\right) .{ }^{9}$ We refer to $\widetilde{x}_{i}$ as the efficient level of care for activity $f_{i}$. It is the level of care at which the marginal cost of care equals the marginal benefit (the marginal reduction in expected harm).

Under strict liability the injurer's problem is identical to the social goal. This is because strict liability forces the injurer to internalize the total social costs of her activities. Hence, she will take efficient care in each activity. Under negligence the injurer's problem is

$$
\min _{x_{1}, \ldots, x_{m} \geq 0} \sum_{i=1}^{m} c\left(x_{i}\right)+h_{i}\left(x_{i}\right) \chi\left(x_{i}<\bar{x}_{i}\right)
$$

where $\bar{x}_{i}$ is the due care standard for activity $f_{i}$ and $\chi\left(x_{i}<\bar{x}_{i}\right)=1$ if $x_{i}<\bar{x}_{i}$, 0 otherwise. If the court sets $\bar{x}_{i}=\widetilde{x}_{i}$ for all $i$, then the injurer takes efficient care in each activity. The reason is twofold. First, the injurer will not take more than the efficient level of care, because she faces no liability if her level of care equals or exceeds the efficient level. Second, the injurer will not take less than the efficient level of care, because then she faces strictly liability, which induces her to take efficient care.

The equivalence result follows immediately from the foregoing.

Theorem 2.1 (Equivalence Result) The injurer will take efficient care in each activity under either negligence or strict liability, provided that, in the case of negligence, the court sets the due care standard for each activity equal to the efficient level of care for that activity.

\footnotetext{
${ }^{9}$ Note that $\xi^{\prime}\left(x_{i}\right)=\frac{c^{\prime}\left(x_{i}\right) \tau^{\prime \prime}\left(x_{i}\right)-\tau^{\prime}\left(x_{i}\right) c^{\prime \prime}\left(x_{i}\right)}{\left[\tau^{\prime}\left(x_{i}\right)\right]^{2}}>0$ for all $x_{i}$; hence $\xi$ is invertible.
} 


\section{The Unawareness Model}

We model unawareness following Karni and Vierø (2013). The primitives of the model are a finite set $F$ of feasible acts and a finite set $Z$ of feasible consequences. In our setting the feasible acts are the injurer's available activities and the feasible consequences are the potential harms to the victim. States are functions from the set of acts to the set of consequences. A state assigns a consequence to each act. The set of all possible states, $Z^{F}$, defines the conceivable state space. With $m$ acts and $n$ consequences, there are $n^{m}$ conceivable states.

The agents and the court (collectively, the parties) originally conceive the sets of acts and consequences to be $F=\left\{f_{1}, \ldots, f_{m}\right\}$ and $Z=\left\{z_{1}, \ldots, z_{n}\right\}$. The conceivable state space is $Z^{F}=\left\{s_{1}, \ldots, s_{n^{m}}\right\}$, where each state $s \in Z^{F}$ is a vector of length $m$, the $i$ th element of which, $s^{i}$, is the consequence $z_{j} \in Z$ produced by act $f_{i} \in F$ in that state of the world.

An act-consequence link, or link, is a causal relationship between an act and a consequence. The conceivable state space admits all conceivable links. However, the parties may perceive one or more links as infeasible, which brings them to nullify the states that admit such links. We refer to these as null states and denote them by $N \subset Z^{F}$. Taking only the non-null states defines the feasible state space, $S \equiv Z^{F} \backslash N$. When $N \neq \emptyset$, there are $\prod_{i=1}^{m}\left(n-\nu_{i}\right)$ feasible states, where $\nu_{i}$ denotes the number of nullified links involving act $f_{i}$.

The parties have common beliefs represented by a probability distribution $p$ on the conceivable state space, $Z^{F}$. The support set of $p$ is the feasible state space, $S$. That is, the parties assign non-zero probability to each non-null state.

The parties may initially fail to conceive one or more acts or consequences or to perceive as feasible one or more conceivable links. We refer to such failures of conception or perception as unawareness. However, the parties may later discover a new act or consequence, which expands both the feasible state space and the conceivable state space, or a new link, which expands the feasible state space but not the conceivable state space. ${ }^{10}$ We refer to such discoveries and expansions as growing awareness.

In the wake of growing awareness, the parties' beliefs update in a way that preserves the relative likelihoods of the events in the original feasible state space. In each case of growing awareness, probability mass shifts proportionally away from the events in the original feasible state space to the new events in the expanded feasible state space. In the case of a new act or consequence, the new events in the expanded feasible state space are also new events in the

\footnotetext{
${ }^{10}$ To be clear, by "new" we mean "not previously conceived" in the case of acts and consequences, and "previously conceived but perceived as infeasible" in the case of links.
} 
expanded conceivable state space. In the case of a new link, the new events in the expanded feasible state space are formerly null events in the original conceivable state space.

Karni and Vierø (2013) refer to this updating as Reverse Bayesianism. Let $\widehat{S}$ denote the expanded feasible state space and $\widehat{p}$ denote the parties' updated beliefs. Formally, Reverse Bayesianism implies: (i) in the case of a new consequence or link, $p(s) / p(t)=\widehat{p}(s) / \widehat{p}(t)$ for all $s, t \in S$; and (ii) in the case of a new act, $p(s) / p(t)=\widehat{p}(E(s)) / \widehat{p}(E(t))$ for all $s, t \in S$, where $E(s)$ denotes the event in $\widehat{S}$ that corresponds to state $s$ in $S$; that is, $E(s) \equiv\left\{t \in \widehat{S}: t^{i}=s^{i}, \forall i \neq m+1\right\}$ (assuming the new act is $f_{m+1}$ ).

In Chakravarty et al. (2022) we show how strengthening Reverse Bayesianism by assuming Act Independence pins down $\widehat{p}$. We define Act Independence formally below.

Assumption 3.1 (Act Independence) Let $A_{i}\left(z_{j}\right) \subset \widehat{S}$ denote the event that act $f_{i}$ yields consequence $z_{j}$; that is, $A_{i}\left(z_{j}\right) \equiv\left\{t \in \widehat{S}: t^{i}=z_{j}\right\}$ is the collection of states in which act $f_{i}$ yields consequence $z_{j}$. We refer to events of this type as act events, and for each act event $A_{i}\left(z_{j}\right)$ we refer to the act $f_{i}$ as the predicate act. Act Independence holds if for every collection of act events in $\widehat{S}$ such that no two act events have the same predicate act, the act events in the collection are mutually independent.

Act Independence implies additional restrictions on $\widehat{p}$. Observe that we can express each state $s=\left(s^{1}, \ldots, s^{m}\right)$ as the intersection of a unique collection of act events: $s=\bigcap_{i} A_{i}\left(s^{i}\right)$. We refer to this collection as the constituent act events for state $s$. Act Independence implies that the probability of state $s$ equals the product of the probabilities of its constituent act events: $\widehat{p}(s)=\prod_{i} \widehat{p}\left(A_{i}\left(s^{i}\right)\right)$. Act Independence also implies that for any act event $A_{i}\left(z_{j}\right)$, its conditional probability given any collection of other act events equals its unconditional probability. In other words, Act Independence implies that the probability that act $f_{i}$ yields consequence $z_{j}$ is independent of the outcomes of any and all other acts $f_{l}, i \neq l$.

\section{Growing Awareness: Legal Cases}

Instances of growing awareness that are relevant to tort law include the discovery of a new and potentially harmful product or technology (new act), the discovery of a new disease or injury (new consequence), or the discovery that a known product can cause a known injury in a previously unknown way (new link). We list below a few illustrative examples. 


\subsection{New Acts}

Social media McApline v. Bercow, which we discuss above in the Introduction, is an example of a tort case involving a new act - the use of social media (specifically, Twitter).

Fracking Modern day hydraulic fracturing, or "fracking," was developed by George Mitchell in the late 1990s, though its origins can be traced to the 1860s (Gold, 2014). In Ely v. Cabot Oil and Gas Corporation, a Pennsylvania jury found in favor of nine plaintiffs on claims that the defendant's fracking activity at two natural gas wells in Susquehanna County in the mid2000s was negligent and caused the plaintiffs' compensable nuisance injuries by interfering with and damaging the plaintiffs' access to water and their enjoyment of their property. The gravamen of the plaintiffs' complaint was that the defendant's fracking activity negligently permitted methane to flow into underground aquifers that wound up polluting the plaintiffs' water wells. ${ }^{11}$ Less than two years after the jury verdict in 2016, and less than three months after the case was finally settled in 2017, the defendant and 25 other major oil and gas companies, under the auspices of the American Petroleum Institute, announced that they were launching a new program, called the Environmental Partnership, focused on reducing emissions of methane and other pollutants from the natural gas sector (Henry, 2017).

\subsection{New Consequences}

HIV / AIDS The first HIV/AIDS cases were reported in the United States in 1981 (U.S. Centers for Disease Control and Prevention, 2011). In Quintana v. United Blood Services, a Denver jury held the defendant liable to the plaintiff for negligently supplying her with HIV contaminated blood in 1983 (Talavera, 1993). ${ }^{12}$ In the three decades since the case was filed, U.S. blood banks, through "the use of donor educational material, specific deferral questions, and advances in HIV donor testing . . . have reduced the risk of HIV transmission from blood transfusion from about 1 in 2500 units to a current estimated residual risk of about 1 in 1.47 million transfusions" (U.S. Food and Drug Administration, 2015, p. 79914).

\footnotetext{
${ }^{11}$ See 2017 WL 1196510 (M.D. Pa. 2017) (denying defendant's motion for judgment as a matter of law but granting its motion for a new trial). The case settled before the second trial.

${ }^{12}$ The jury also held the defendant liable to the plaintiff's husband for negligent infliction of emotional distress and loss of consortium. The case was initially filed in the late 1980s and the final verdict was rendered in 1992 (Talavera, 1993).
} 
Mad cow disease Mad cow disease, formally known as bovine spongiform encephalopathy (BSE), was first discovered in the United Kingdom in 1986 (Collee and Bradley, 1997). In 2008, Ridley Inc., a Winnipeg cattle feed supplier, settled a class action by Canadian cattle farmers claiming that the defendant negligently supplied them with BSE contaminated feed in the early 1990s (Dowd, 2008). In a related class action filed in 2005, the plaintiffs accused the Canadian government of negligently allowing BSE infected cattle to be imported into Canada in the late 1980s and used for feed ingredients in the early 1990s (Kienlen, 2017). Two years after the class action was filed, the Canadian government implemented an enhanced feed ban aimed at preventing the spread of BSE (Stephenson, 2015). ${ }^{13}$

\subsection{New Links}

Agent Orange and cancer Agent Orange, a chemical herbicide, was developed in the 1940s and used by the U.S. military as part of its herbicidal warfare program, Operation Ranch Hand, during the Vietnam War (Schuck, 1987). The first recorded case of cancer hails from ancient Egypt, and the origin of the word cancer is credited to the ancient Greek physician Hippocrates (Sudhakar, 2009). In In re Agent Orange Product Liability Litigation, Vietnam veterans brought a class action against the manufacturers of Agent Orange alleging, inter alia, that their exposure to Agent Orange in Vietnam resulted in a variety of cancers and other diseases in the veterans and birth defects in their children. ${ }^{14}$ The class action was filed in 1979. In 1983, seven months before the parties reached a settlement, Dow Chemical Company, the lead defendant in the class action, announced that it was permanently discontinuing production of 2,4,5-trichlorophenoxyacetic acid, the component of Agent Orange that was responsible for its toxicity (Holusha, 1983; American Chemical Society, 1985).

American football and CTE The National Football League (NFL) was founded in 1920 (Crepeau, 2014). Chronic traumatic encephalopathy (CTE), a neurodegenerative brain disease found in people with a history of repetitive head injuries, was first reported in boxers in 1928 and in NFL players in 2005 (Lindsley, 2017). In In re National Football League Players Concussion Injury Litigation, retired NFL players brought a class action against the NFL alleging that the league had failed to take reasonable actions to protect the players from CTE

\footnotetext{
${ }^{13}$ The class action was ultimately dismissed in 2022, with the court finding that Canada was not negligent (Briere, 2022).

${ }^{14}$ See 597 F. Supp. 740 (E.D.N.Y. 1984). The case was settled for $\$ 180$ million.
} 
and other chronic risks of head injuries. ${ }^{15}$ The action was filed in 2011. Seven months before the parties reached a settlement in 2013, the NFL announced a new concussion protocol, which includes guidelines for sideline evaluation and rules on preseason education, baseline testing, and the establishment of personnel to conduct evaluations (Flynn, 2016).

In each of the foregoing examples the initial lawsuit increased awareness and precaution undertaken by injurers, which is compatible with our arguments.

\section{$5 \quad$ Illustrative Results}

In this section and the next, we compare and contrast negligence and strict liability in a world with unawareness. Throughout, we assume the parties are fully rational apart from unawareness. We further assume that when the parties are unaware of an act, consequence, or link, their beliefs, although incorrect with respect to the absolute likelihoods of events, are nevertheless correct with respect to the relative likelihoods of non-null events. Without this assumption, the parties could not have correct beliefs when they become fully aware, which would be inconsistent with the standard accident model.

In this section we analyze a simple model, which illustrates our main ideas. We extend the results to a more general model in the next section. In both models, for simplicity, we maintain the assumption that $c(\cdot)$ and $\tau(\cdot)$ are known to all parties and are the same for all activities. The latter assumption is without loss of generality given the former assumption.

The simple model has two activities, $F=\left\{f_{1}, f_{2}\right\}$; two consequences, $Z=\left\{z_{1}, z_{2}\right\}$, where $z_{1}=0$ (no harm) and $z_{2}>0$ (positive harm); quadratic care costs, $c\left(x_{i}\right)=\left(x_{i}\right)^{2}$; and linear expected harm reduction, $\tau\left(x_{i}\right)=\left(1-x_{i}\right){ }^{16}$ The conceivable state space, $Z^{F}$, comprises four states: $s_{1}=(0,0), s_{2}=\left(0, z_{2}\right), s_{3}=\left(z_{2}, 0\right)$, and $s_{4}=\left(z_{2}, z_{2}\right)$. Let $p_{k} \equiv p\left(s_{k}\right), k=1, \ldots, 4$, denote the parties' common beliefs on $Z^{F}$.

\subsection{New Link}

We start with the case of a new link. We assume the parties initially perceive activity $f_{1}$ as safe (i.e., incapable of causing harm) and activity $f_{2}$ as risky (i.e., capable of causing harm). That is, we assume they initially perceive the event $A_{1}\left(z_{2}\right)=\left\{s_{3}, s_{4}\right\}$ as infeasible (null).

\footnotetext{
${ }^{15}$ See 821 F.3d 410 (3d Cir. 2016). The case was settled for approximately $\$ 1$ billion.

${ }^{16}$ To preserve the condition $\tau\left(x_{i}\right)>0$ for all $x_{i}$, we assume $x_{i} \in[0,1)$ in this section.
} 
This implies $p_{3}=p_{4}=0$. We can depict the original feasible state space, $S \subset Z^{F}$, as follows:

\begin{tabular}{c|cc}
$p$ & $p_{1}$ & $p_{2}$ \\
\hline \hline$F \backslash S$ & $s_{1}$ & $s_{2}$ \\
\hline$f_{1}$ & 0 & 0 \\
$f_{2}$ & 0 & $z_{2}$
\end{tabular}.

Given $S$ and $p$, the efficient levels of care are $\widetilde{x}_{1}=0$ and $\widetilde{x}_{2}=\frac{p_{2} z_{2}}{2}$. Under negligence, the court stipulates $\bar{x}_{1}=\widetilde{x}_{1}$ and $\bar{x}_{2}=\widetilde{x}_{2}$ as the due care standards for $f_{1}$ and $f_{2}$, respectively.

Suppose the parties discover that activity $f_{1}$ is risky. In particular, suppose that the injurer engages in $f_{1}$, that it results in harm $z_{2}$, and that the victim brings a tort suit against the injurer. The feasible state space expands from two to four states to reflect the discovery that $f_{1}$ can yield $z_{2},{ }^{17}$ and the parties update their beliefs to $\widehat{p}$ :

\begin{tabular}{c|cccc}
$\widehat{p}$ & $\widehat{p}_{1}$ & $\widehat{p}_{2}$ & $\widehat{p}_{3}$ & $\widehat{p}_{4}$ \\
\hline \hline$F \backslash \widehat{S}$ & $s_{1}$ & $s_{2}$ & $s_{3}$ & $s_{4}$ \\
\hline$f_{1}$ & 0 & 0 & $z_{2}$ & $z_{2}$ \\
$f_{2}$ & 0 & $z_{2}$ & 0 & $z_{2}$
\end{tabular}.

We assume that, by virtue of the suit, the parties learn that activity $f_{1}$ yields harm $z_{2}$ with probability $\delta>0$. The fact is the parties have the incentive to expend resources to develop this knowledge. As the Hand formula makes plain, ${ }^{18}$ the probability of harm is an

${ }^{17}$ The feasible state space now coincides with the conceivable state space, i.e., $\widehat{S}=Z^{F}$.

${ }^{18}$ The Hand formula is a famous passage from the negligence case, United States v. Carroll Towing Co., 159 F.2d 169 (2d Cir. 1947). The case concerned the sinking of the barge Anna C, which took place on January 4, 1944 in New York Harbor. On the day of the accident, the tugboat Carroll, which was operating in New York Harbor, unintentionally caused several other barges to break free from their moorings, which resulted in the sinking of the Anna $C$. The United States, lessee of the Anna C, sued Carroll Towing Co., owner of the Carroll, claiming negligence. The author of the court's opinion, Judge Learned Hand, proposed a formula to determine if the standard of care had been met (p. 173):

Since there are occasions when every vessel will break from her moorings, and since, if she does, she becomes a menace to those about her; the owner's duty, as in other similar situations, to provide against resulting injuries is a function of three variables: (1) The probability that she will break away; (2) the gravity of the resulting injury, if she does; (3) the burden of adequate precautions. Possibly it serves to bring this notion into relief to state it in algebraic terms: if the probability be called P; the injury, L; and the burden, B; liability depends upon whether $\mathrm{B}$ is less than L multiplied by P: i.e., whether B $>$ PL. 
essential component of a negligence case. Even in a strict liability case, the probability of harm is relevant to the issues of foreseeability and proximate cause. ${ }^{19}$

Note that $\delta=\widehat{p}\left(A_{1}\left(z_{2}\right)\right)=\widehat{p}_{3}+\widehat{p}_{4}$ is the total probability of the new states in the expanded feasible state space. It is a measure of the likelihood of the act event of which the parties were previously unaware. Thus, we interpret $\delta$ as the degree of unawareness.

Reverse Bayesianism implies that the relative likelihood of states $s_{1}$ and $s_{2}$ remains the same after updating, hence

$$
\frac{p_{1}}{p_{2}}=\frac{\widehat{p}_{1}}{\widehat{p}_{2}} .
$$

Note that $p_{1}+p_{2}=1$. Because $\widehat{p}_{1}+\widehat{p}_{2}=1-\delta$, it follows that $\widehat{p}_{1}=(1-\delta) p_{1}$ and $\widehat{p}_{2}=(1-\delta) p_{2}$. Act Independence implies that the odds that activity $f_{2}$ results in harm is the same whether or not activity $f_{1}$ results in harm, hence

$$
\frac{\widehat{p}_{1}}{\widehat{p}_{2}}=\frac{\widehat{p}_{3}}{\widehat{p}_{4}} .
$$

Because $\widehat{p}_{3}+\widehat{p}_{4}=\delta$, it follows that $\widehat{p}_{3}=\delta p_{1}$ and $\widehat{p}_{4}=\delta p_{2}$. Thus, Reverse Bayesianism (and knowledge of $\delta$ ) pins down $\widehat{p}$. The following proposition recaps the foregoing results.

Proposition 5.1 Assume there are two acts and two consequences. Suppose the parties discover a new link between an act and a consequence and learn that the corresponding new act event has probability $\delta$. Under Reverse Bayesianism and Act Independence, the updated probabilities are $\widehat{p}_{1}=(1-\delta) p_{1}, \widehat{p}_{2}=(1-\delta) p_{2}, \widehat{p}_{3}=\delta p_{1}$, and $\widehat{p}_{4}=\delta p_{2}$.

Remark 5.1 Note that $p$ is the Bayesian update of $\widehat{p}$ conditional on the event $S=\left\{s_{1}, s_{2}\right\}$ (i.e., the original feasible state space). Hence the term Reverse Bayesianism.

Given $\widehat{S}$ and $\widehat{p}$, the efficient levels of care are

$$
\widehat{\widetilde{x}}_{1}=\frac{\left(\widehat{p}_{3}+\widehat{p}_{4}\right) z_{2}}{2}=\frac{\delta z_{2}}{2} \text { and } \quad \widehat{\widetilde{x}}_{2}=\frac{\left(\widehat{p}_{2}+\widehat{p}_{4}\right) z_{2}}{2}=\frac{p_{2} z_{2}}{2}
$$

Note that $\widehat{\widetilde{x}}_{1}>\widetilde{x}_{1}$ but $\widehat{\widetilde{x}}_{2}=\widetilde{x}_{2}$. Thus, the discovery that activity $f_{1}$ is risky necessitates the stipulation of a new due care standard for $f_{1}$ but not for $f_{2}$.

Under negligence, the court stipulates $\widehat{\bar{x}}_{1}=\widehat{\widetilde{x}}_{1}$ as the new due care standard for $f_{1}$ and holds the injurer liable to pay damages of $z_{2}$ to the victim. ${ }^{20}$ This makes outsiders aware

\footnotetext{
${ }^{19}$ Alternatively, we could assume the court learns $\delta$ by virtue of a sequence of suits (cf. Ott and Schäfer, 1997; Feess and Wohlschlegel, 2006).

${ }^{20}$ Recall that $\bar{x}_{1}=\widetilde{x}_{1}=0$ before the parties discover that $f_{1}$ is potentially harmful. Under negligence, therefore, the injurer will have exercised no care in conjunction with $f_{1}$. However, even if the court does
} 
that $f_{1}$ is risky. Moreover, they can deduce $\delta$ from $\widehat{\bar{x}}_{1}$; specifically, $\delta=2 \widehat{\widetilde{x}}_{1} / z_{2}$. As a result, they can learn $\widehat{p}$ and $\widehat{h}_{1}\left(x_{1}\right)=\delta z_{2} \tau\left(x_{1}\right)$, without expending additional resources to learn about $\delta$. This is the information other injurers need in order to take efficient care.

Under strict liability, the court simply holds the injurer liable to pay damages of $z_{2}$ to the victim. This makes outsiders aware that $f_{1}$ is risky. However, they cannot deduce $\delta$ or learn $\widehat{p}$ or $\widehat{h}_{1}\left(x_{1}\right)$. Hence, other injurers lack sufficient information to take efficient care.

Remark 5.2 If $c(\cdot)$ and $\tau(\cdot)$ are the same for all injurers, then knowledge of $\widehat{h}_{1}\left(x_{1}\right)$ is not strictly necessary for them to take efficient care under negligence. They can just blindly adopt $\widehat{\bar{x}}_{1}$ as their level of care, without bothering to deduce $\delta$ from $\widehat{\bar{x}}_{1}$ and learn $\widehat{h}_{1}\left(x_{1}\right)$. If, however, either $c(\cdot)$ or $\tau(\cdot)$ varies across injurers, then they need to deduce $\delta$ from $\widehat{\bar{x}}_{1}$ in order to learn their own $\widehat{h}_{1}\left(x_{1}\right)$, which is necessary for them to take efficient care. Moreover, injurers always need to know $\widehat{h}_{1}\left(x_{1}\right)$ in order to take efficient care under strict liability, because the court does not stipulate a due care standard in this case.

\subsection{New Act}

We next consider the case of a new act. Assume the original feasible state space coincides with the conceivable state space (i.e., $S=Z^{F}$ ):

\begin{tabular}{c|cccc}
$p$ & $p_{1}$ & $p_{2}$ & $p_{3}$ & $p_{4}$ \\
\hline \hline$F \backslash S$ & $s_{1}$ & $s_{2}$ & $s_{3}$ & $s_{4}$ \\
\hline$f_{1}$ & 0 & 0 & $z_{2}$ & $z_{2}$ \\
$f_{2}$ & 0 & $z_{2}$ & 0 & $z_{2}$
\end{tabular}.

The efficient levels of care are $\widetilde{x}_{1}=\frac{\left(p_{3}+p_{4}\right) z_{2}}{2}$ and $\widetilde{x}_{2}=\frac{\left(p_{2}+p_{4}\right) z_{2}}{2}$. Under negligence, the court stipulates $\bar{x}_{1}=\widetilde{x}_{1}$ and $\bar{x}_{2}=\widetilde{x}_{2}$ as the due care standards for $f_{1}$ and $f_{2}$, respectively.

Suppose the parties discover a new activity, $f_{3}$, which has the potential to cause harm. In particular, suppose that the injurer discovers and engages in $f_{3}$, that it results in $z_{2}$, and that the victim brings a tort suit against the injurer before the court. The feasible state

not hold the injurer liable and award damages (perhaps by recognizing a civil ex post facto doctrine which prohibits retroactive application of a due care standard in a negligence suit), our results below would not change, because the world already knows the set of potential harms. 
space expands from four to eight states:

\begin{tabular}{c|cccccccc}
$\widehat{p}$ & $\widehat{p}_{1}$ & $\widehat{p}_{2}$ & $\widehat{p}_{3}$ & $\widehat{p}_{4}$ & $\widehat{p}_{5}$ & $\widehat{p}_{6}$ & $\widehat{p}_{7}$ & $\widehat{p}_{8}$ \\
\hline \hline$F \backslash \widehat{S}$ & $s_{1}$ & $s_{2}$ & $s_{3}$ & $s_{4}$ & $s_{5}$ & $s_{6}$ & $s_{7}$ & $s_{8}$ \\
\hline$f_{1}$ & 0 & 0 & $z_{2}$ & $z_{2}$ & 0 & 0 & $z_{2}$ & $z_{2}$ \\
$f_{2}$ & 0 & $z_{2}$ & 0 & $z_{2}$ & 0 & $z_{2}$ & 0 & $z_{2}$ \\
$f_{3}$ & 0 & 0 & 0 & 0 & $z_{2}$ & $z_{2}$ & $z_{2}$ & $z_{2}$
\end{tabular}

The expanded feasible state space contains two copies of the original feasible state space, one in which $f_{3}$ results in no harm and one in which $f_{3}$ results in harm $z_{2}$. Stated differently, the expanded space splits each of the original states into two depending on whether or not $f_{3}$ yields positive harm. For each original state there is a corresponding event in the expanded feasible state space. For instance, the event $\left\{s_{1}, s_{5}\right\} \in \widehat{S}$ corresponds to state $s_{1} \in S$, the event $\left\{s_{2}, s_{6}\right\} \in \widehat{S}$ corresponds to state $s_{2} \in S$, and so forth. ${ }^{21}$

As before, we assume that, by virtue of the suit, the parties learn that activity $f_{3}$ yields harm $z_{2}$ with probability $\delta>0$. By Reverse Bayesiansim, $\frac{p_{1}}{p_{2}}=\frac{\widehat{p}_{1}+\widehat{p}_{5}}{\widehat{p}_{2}+\widehat{p}_{6}}$. By Act independence, $\frac{\widehat{p}_{1}}{\widehat{p}_{2}}=\frac{\widehat{p}_{5}}{\widehat{p}_{6}}$. Substituting,

$$
\frac{p_{1}}{p_{2}}=\frac{\widehat{p}_{1}+\frac{\widehat{p}_{1} \widehat{p}_{6}}{\widehat{p}_{2}}}{\widehat{p}_{2}+\widehat{p}_{6}}=\frac{\widehat{p}_{1}}{\widehat{p}_{2}}=\frac{\widehat{p}_{5}}{\widehat{p}_{6}} .
$$

By similar reasoning, $\frac{p_{2}}{p_{3}}=\frac{\widehat{p}_{2}}{\widehat{p}_{3}}=\frac{\widehat{p}_{6}}{\widehat{p}_{7}}$ and $\frac{p_{3}}{p_{4}}=\frac{\widehat{p}_{3}}{\widehat{p}_{4}}=\frac{\widehat{p}_{7}}{\widehat{p}_{8}}$. Because $p_{1}+p_{2}+p_{3}+p_{4}=1$, $\widehat{p}_{1}+\widehat{p}_{2}+\widehat{p}_{3}+\widehat{p}_{4}=1-\delta$, and $\widehat{p}_{5}+\widehat{p}_{6}+\widehat{p}_{7}+\widehat{p}_{8}=\delta$, we have the following result.

Proposition 5.2 Assume there are two acts and two consequences. Suppose the parties discover a new act, which they link to both consequences, and learn that the corresponding new act events have probabilities $1-\delta$ and $\delta$. Under Reverse Bayesiansm and Act Independence, the updated probabilities are $\widehat{p}_{1}=(1-\delta) p_{1}, \widehat{p}_{2}=(1-\delta) p_{2}, \widehat{p}_{3}=(1-\delta) p_{3}, \widehat{p}_{4}=(1-\delta) p_{4}$, $\widehat{p}_{5}=\delta p_{1}, \widehat{p}_{6}=\delta p_{2}, \widehat{p}_{7}=\delta p_{3}$, and $\widehat{p}_{8}=\delta p_{4}$.

\footnotetext{
${ }^{21}$ Note that the conceivable state space also expands from four to eight states, so $\widehat{S}=Z^{\widehat{F}}$.
} 
Given $\widehat{S}$ and $\widehat{p}$, the efficient levels of care are

$$
\begin{aligned}
\widehat{\widetilde{x}}_{1} & =\frac{\left(\widehat{p}_{3}+\widehat{p}_{4}+\widehat{p}_{7}+\widehat{p}_{8}\right) z_{2}}{2}=\frac{\left(p_{3}+p_{4}\right) z_{2}}{2}, \\
\widehat{\widetilde{x}}_{2} & =\frac{\left(\widehat{p}_{2}+\widehat{p}_{4}+\widehat{p}_{6}+\widehat{p}_{8}\right) z_{2}}{2}=\frac{\left(p_{2}+p_{4}\right) z_{2}}{2}, \\
\text { and } \quad \widehat{\widetilde{x}}_{3} & =\frac{\left(\widehat{p}_{5}+\widehat{p}_{6}+\widehat{p}_{7}+\widehat{p}_{8}\right) z_{2}}{2}=\frac{\delta z_{2}}{2} .
\end{aligned}
$$

Thus, the discovery of $f_{3}$ necessitates the stipulation of a new due care standard, $\widehat{\bar{x}}_{3}$, while the due care standards for $f_{1}$ and $f_{2}$ are unchanged.

Under negligence, the court stipulates $\widehat{\bar{x}}_{3}=\widehat{\widetilde{x}}_{3}$ as the due care standard for the new activity $f_{3}$ and holds the injurer liable to pay damages of $z_{2}$ to the victim. ${ }^{22}$ This makes outsiders aware of $f_{3}$ (and that it is risky). Moreover, they can deduce $\delta$ from $\widehat{\bar{x}}_{3}$; specifically, $\delta=2 \widehat{\widetilde{x}}_{3} / z_{2}$. As a result, they can learn $\widehat{p}$ and $\widehat{h}_{3}\left(x_{3}\right)=\delta z_{2} \tau\left(x_{3}\right)$. This is sufficient information for other injurers to take efficient care.

As before, however, strict liability does not reveal sufficient information to other injurers. Under strict liability, the court simply holds the injurer liable to pay damages of $z_{2}$ to the victim. This makes outsiders aware of $f_{3}$ (and that it is risky), but they cannot deduce $\delta$ or learn $\widehat{p}$ or $\widehat{h}_{3}\left(x_{3}\right)$.

\subsection{New Consequence}

Lastly, we consider the case of a new consequence. As before, we assume $S=Z^{F}$ :

\begin{tabular}{c|cccc}
$p$ & $p_{1}$ & $p_{2}$ & $p_{3}$ & $p_{4}$ \\
\hline \hline$F \backslash S$ & $s_{1}$ & $s_{2}$ & $s_{3}$ & $s_{4}$ \\
\hline$f_{1}$ & 0 & 0 & $z_{2}$ & $z_{2}$ \\
$f_{2}$ & 0 & $z_{2}$ & 0 & $z_{2}$
\end{tabular}.

The efficient levels of care are $\widetilde{x}_{1}=\frac{\left(p_{3}+p_{4}\right) z_{2}}{2}$ and $\widetilde{x}_{2}=\frac{\left(p_{2}+p_{4}\right) z_{2}}{2}$. Under negligence, the court stipulates $\bar{x}_{1}=\widetilde{x}_{1}$ and $\bar{x}_{2}=\widetilde{x}_{2}$ as the due care standards for $f_{1}$ and $f_{2}$, respectively.

Suppose the parties discover a new consequence, $z_{3}>z_{2}$, which they link to $f_{1}$ and $f_{2}$. In particular, suppose that the injurer engages in $f_{1}$ and $f_{2}$, that each results in harm $z_{3}$, and that the victim brings a tort suit against the injurer before the court. The feasible state

\footnotetext{
${ }^{22}$ Again, because the world already knows the set of potential harms, our results below would not change if the court does not hold the injurer liable and award damages.
} 
space expands from four to nine states:

\begin{tabular}{c|ccccccccc}
$\widehat{p}$ & $\widehat{p}_{1}$ & $\widehat{p}_{2}$ & $\widehat{p}_{3}$ & $\widehat{p}_{4}$ & $\widehat{p}_{5}$ & $\widehat{p}_{6}$ & $\widehat{p}_{7}$ & $\widehat{p}_{8}$ & $\widehat{p}_{9}$ \\
\hline \hline$F \backslash \widehat{S}$ & $s_{1}$ & $s_{2}$ & $s_{3}$ & $s_{4}$ & $s_{5}$ & $s_{6}$ & $s_{7}$ & $s_{8}$ & $s_{9}$ \\
\hline$f_{1}$ & 0 & 0 & $z_{2}$ & $z_{2}$ & $z_{3}$ & $z_{3}$ & 0 & $z_{2}$ & $z_{3}$ \\
$f_{2}$ & 0 & $z_{2}$ & 0 & $z_{2}$ & 0 & $z_{2}$ & $z_{3}$ & $z_{3}$ & $z_{3}$
\end{tabular}.

The new state space is characterized by three events, one in which $f_{1}$ results in no harm, one in which $f_{1}$ results in harm $z_{2}$, and one in which $f_{1}$ results in harm $z_{3}$. Each event contains three states, one in which $f_{2}$ results in no harm, one in which $f_{2}$ results in harm $z_{2}$, and one in which $f_{2}$ results in harm $z_{3}{ }^{23}$

We assume that, by virtue of the suit, the parties learn that activity $f_{1}$ yields $z_{3}$ with probability $\alpha_{1}>0$ and that activity $f_{2}$ yields $z_{3}$ with probability $\alpha_{2}>0$. (This is analogous to assuming that the parties learn the probabilities of the new act event(s) in the previous cases.) As before, the degree of unawareness is the total probability of the new states, i.e., $\delta=\widehat{p}_{5}+\cdots+\widehat{p}_{9}$. Under Act Independence, $1-\delta=\widehat{p}\left(A_{1}^{\mathrm{c}}\left(z_{3}\right) \bigcap A_{2}^{\mathrm{c}}\left(z_{3}\right)\right)=\left(1-\alpha_{1}\right)\left(1-\alpha_{2}\right) .{ }^{24}$ The ensuing result follows.

Proposition 5.3 Assume there are two acts and two consequences. Suppose the parties discover a new consequence, which they link to both acts, and learn that the corresponding new act events have probabilities $\alpha_{1}$ and $\alpha_{2}$. Under Reverse Bayesianism and Act Independence, the updated probabilities are $\widehat{p}_{1}=(1-\delta) p_{1}, \widehat{p}_{2}=(1-\delta) p_{2}, \widehat{p}_{3}=(1-\delta) p_{3}, \widehat{p}_{4}=(1-\delta) p_{4}$, $\widehat{p}_{5}=\alpha_{1}\left(1-\alpha_{2}\right)\left(p_{1}+p_{3}\right), \widehat{p}_{6}=\alpha_{1}\left(1-\alpha_{2}\right)\left(p_{2}+p_{4}\right), \widehat{p}_{7}=\left(1-\alpha_{1}\right) \alpha_{2}\left(p_{1}+p_{2}\right)$, $\widehat{p}_{8}=\left(1-\alpha_{1}\right) \alpha_{2}\left(p_{3}+p_{4}\right)$, and $\widehat{p}_{9}=\alpha_{1} \alpha_{2}$.

Given $\widehat{S}$ and $\widehat{p}$, the efficient levels of care are

$$
\begin{aligned}
& \widehat{\widetilde{x}}_{1}=\frac{\left(\widehat{p}_{3}+\widehat{p}_{4}+\widehat{p}_{8}\right) z_{2}+\left(\widehat{p}_{5}+\widehat{p}_{6}+\widehat{p}_{9}\right) z_{3}}{2}=\frac{\left(1-\alpha_{1}\right)\left(p_{3}+p_{4}\right) z_{2}+\alpha_{1} z_{3}}{2} \\
& \text { and } \quad \widehat{\widetilde{x}}_{2}=\frac{\left(\widehat{p}_{2}+\widehat{p}_{4}+\widehat{p}_{6}\right) z_{2}+\left(\widehat{p}_{7}+\widehat{p}_{8}+\widehat{p}_{9}\right) z_{3}}{2}=\frac{\left(1-\alpha_{2}\right)\left(p_{2}+p_{4}\right) z_{2}+\alpha_{2} z_{3}}{2} .
\end{aligned}
$$

Note that $\widehat{\widetilde{x}}_{1}>\widetilde{x}_{1}$ and $\widehat{\widetilde{x}}_{2}>\widetilde{x}_{2}$. Thus, the discovery of $z_{3}$ necessitates the stipulation of new due care standards for both $f_{1}$ and $f_{2}$.

${ }^{23}$ Note that the conceivable state space also expands from four to nine states, so $\widehat{S}=\widehat{Z}^{F}$.

${ }^{24}$ For the avoidance of doubt, $A_{i}^{\mathrm{c}}\left(z_{j}\right)$ denotes the complement of the act event $A_{i}\left(z_{j}\right)$. 
Under negligence, the court stipulates $\widehat{\bar{x}}_{1}=\widehat{\widetilde{x}}_{1}$ and $\widehat{\bar{x}}_{2}=\widehat{\widetilde{x}}_{2}$ as the new due care standards for $f_{1}$ and $f_{2}$, respectively. The court holds the injurer liable to pay damages of $z_{3}$ to the victim with respect to each of $f_{1}$ and $f_{2}$. This makes outsiders aware of $z_{3}$ (and that it is linked to $f_{1}$ and $\left.f_{2}\right){ }^{25}$ Moreover, they can deduce $\alpha_{1}$ and $\alpha_{2}$ (and hence $\delta$ ) from $\widehat{\bar{x}}_{1}$ and $\widehat{\bar{x}}_{2}$ :

$$
\alpha_{1}=\frac{p_{3} z_{2}-2 \widehat{\widetilde{x}}_{1}+p_{4} z_{2}}{p_{3} z_{2}-z_{3}+p_{4} z_{2}} \quad \text { and } \quad \alpha_{2}=\frac{p_{2} z_{2}-2 \widehat{\widetilde{x}}_{2}+p_{4} z_{2}}{p_{2} z_{2}-z_{3}+p_{4} z_{2}}
$$

As a result, they can learn $\widehat{p}$ and

$\widehat{h}_{1}\left(x_{1}\right)=\left[\left(1-\alpha_{1}\right)\left(p_{3}+p_{4}\right) z_{2}+\alpha_{1} z_{3}\right] \tau\left(x_{1}\right) \quad$ and $\quad \widehat{h}_{2}\left(x_{2}\right)=\left[\left(1-\alpha_{2}\right)\left(p_{2}+p_{4}\right) z_{2}+\alpha_{2} z_{3}\right] \tau\left(x_{2}\right)$,

without expending additional resources to learn about $\alpha_{1}$ and $\alpha_{2}$. Thus, negligence reveals sufficient information for other injurers to take efficient care.

Under strict liability, the court simply holds the injurer liable to pay damages of $z_{3}$ for each instance of harm. This makes outsiders aware of $z_{3}$ (and that it is linked to $f_{1}$ and $f_{2}$ ). However, they cannot deduce $\alpha_{1}$ or $\alpha_{2}$ or learn $\widehat{p}, \widehat{h}_{1}\left(x_{1}\right)$, or $\widehat{h}_{2}\left(x_{2}\right)$. As before, strict liability yields insufficient information for other injurers to take efficient care.

\subsection{Act Independence}

Before turning to the general results, we conclude this section with a few remarks about Act Independence. In short, we argue that it is a useful simplifying assumption, but that it is not crucial. Even without Act Independence, negligence would reveal useful information.

Reverse Bayesianism alone is not sufficient to fully determine the updated probability distribution $\widehat{p}$ in the wake of growing awareness. To borrow a term from the econometrics literature, Reverse Bayesianism only partially identifies $\widehat{p}$. The reason is that Reverse Bayesianism prescribes how probability mass shifts away from non-null states in the original state space to the corresponding states or events in the expanded state space, but it does not dictate how this mass is distributed among the new states. This is where Act Independence comes in. It determines how the shifted probability mass is apportioned among the new states. Together, Reverse Bayesianism and Act Independence fully identify $\widehat{p}$.

\footnotetext{
${ }^{25}$ Even if the court does not hold the injurer liable and award damages, the victim's claims make outsiders aware of $z_{3}$ (and that it is linked to $f_{1}$ and $f_{2}$ ).
} 
How realistic is Act Independence? The answer depends on the nature of the specific activities in question. For instance, the risk that fracking for natural gas results in groundwater contamination is likely to be independent of the risk that importing liquefied natural gas results in a fire or explosion. By contrast, the risk of contracting HIV from sharing drug injection needles is likely to be correlated with the risk of contracting HIV from having unprotected sex, as both depend on the prevalence of HIV in the population.

Because there exist activities whose outcomes are not independent, it is useful to investigate the importance of Act Independence for our results. As above, we consider the simple case of two acts and two consequences.

New link In the case of a new link, Reverse Bayesianism alone implies $\widehat{p}_{1}=(1-\delta) p_{1}$, $\widehat{p}_{2}=(1-\delta) p_{2}$, and $\widehat{p}_{3}+\widehat{p}_{4}=\delta$. Importantly, Reverse Bayesianism alone is not sufficient to separately identify $\widehat{p}_{3}$ and $\widehat{p}_{4}$. As it turns out, this does not create an issue with respect to activity $f_{1}$. Recall that, by assumption, the parties learn $\delta$ (the probability that $f_{1}$ yields $z_{2}$ ). Because the efficient level of care for $f_{1}$ is a function of the sum $\widehat{p}_{3}+\widehat{p}_{4}$, the court can stipulate a new due care standard for $f_{1}$ in terms of $\delta$. This is sufficient to make outsiders aware that $f_{1}$ is potentially harmful. Moreover, they can deduce $\delta$ from the new due care standard for $f_{1}$ and, in turn, learn $\widehat{h}_{1}\left(x_{1}\right)=\delta z_{2} \tau\left(x_{1}\right)$.

Relaxing Act Independence, however, creates ambiguity with respect to the updated risk of activity $f_{2}$. Because the efficient level of care for $f_{2}$ is a function of the sum $\widehat{p}_{2}+\widehat{p}_{4}$, without Act Independence (or another assumption that separately identifies $\widehat{p}_{3}$ and $\widehat{p}_{4}$ ), the court cannot stipulate a precise new due care standard for $f_{2}$. The best the court can do is specify lower and upper bounds, using the knowledge that $\widehat{p}_{4} \in(0, \delta)$. Given these bounds, the best outsiders can do is infer bounds on $\widehat{h}_{2}\left(x_{2}\right)$.

Of course, the ambiguity can be resolved if the parties learn more about $\widehat{p}$. For instance, if the parties learn not only $\delta$ but also either $\widehat{p}_{2}+\widehat{p}_{4}$ (the updated probability that $f_{2}$ yields $z_{2}$ ) or $\widehat{p}_{4}$ (the joint probability that $f_{1}$ and $f_{2}$ yield $z_{2}$ ), this is sufficient to separately identify $\widehat{p}_{3}$ and $\widehat{p}_{4}$. With this, the court can stipulate a precise new due care standard for $f_{2}$, from which outsiders can deduce $\widehat{p}_{2}+\widehat{p}_{4}$ and, in turn, learn $\widehat{h}_{2}\left(x_{2}\right)=\left(\widehat{p}_{2}+\widehat{p}_{4}\right) z_{2} \tau\left(x_{2}\right)$.

New act In the case of a new act, Reverse Bayesianism alone implies $\widehat{p}_{1}+\widehat{p}_{5}=p_{1}$, $\widehat{p}_{2}+\widehat{p}_{6}=p_{2}, \widehat{p}_{3}+\widehat{p}_{7}=p_{3}, \widehat{p}_{4}+\widehat{p}_{8}=p_{4}$, and $\widehat{p}_{5}+\widehat{p}_{6}+\widehat{p}_{7}+\widehat{p}_{8}=\delta .^{26}$ Recall that the

\footnotetext{
${ }^{26}$ See the proof of Proposition 5.2 in the Appendix.
} 
efficient level of care for $f_{1}$ is a function of the sum $\widehat{p}_{3}+\widehat{p}_{4}+\widehat{p}_{7}+\widehat{p}_{8}$; the efficient level of care for $f_{2}$ is a function of the sum $\widehat{p}_{2}+\widehat{p}_{4}+\widehat{p}_{6}+\widehat{p}_{8}$; and the efficient level of care for $f_{3}$ is a function of the sum $\widehat{p}_{5}+\widehat{p}_{6}+\widehat{p}_{7}+\widehat{p}_{8}$. Hence, even without Act Independence, the court's information is sufficiently precise (i) to know that it need not stipulate new due care standards for activities $f_{1}$ and $f_{2}$ and (ii) to stipulate a due care standard for the new activity $f_{3}$. This makes outsiders aware of $f_{3}$ (and that it is risky). Moreover, they can deduce $\delta$ from the due care standard for $f_{3}$ and, in turn, learn $\widehat{h}_{3}\left(x_{3}\right)=\delta z_{2} \tau\left(x_{3}\right)$.

New consequence In the case of a new consequence, Reverse Bayesianism alone implies $\widehat{p}_{1}=(1-\delta) p_{1}, \widehat{p}_{2}=(1-\delta) p_{2}, \widehat{p}_{3}=(1-\delta) p_{3}, \widehat{p}_{4}=(1-\delta) p_{4}$, and $\widehat{p}_{5}+\cdots+\widehat{p}_{9}=\delta .{ }^{27}$ By assumption, the parties learn $\widehat{p}_{5}+\widehat{p}_{6}+\widehat{p}_{9}=\alpha_{1}$ (the probability that $f_{1}$ yields $z_{3}$ ) and $\widehat{p}_{7}+\widehat{p}_{8}+\widehat{p}_{9}=\alpha_{2}$ (the probability that $f_{2}$ yields $z_{3}$ ). Assume the parties also learn $\widehat{p}_{9}$ (the joint probability that $f_{1}$ and $f_{2}$ yield $z_{3}$ ), and let $\widehat{p}_{9}=\gamma$. Note that $\delta=\alpha_{1}+\alpha_{2}-\gamma$.

Recall that the efficient level of care for $f_{1}$ is a function of $\alpha_{1}$ and the sum $\widehat{p}_{3}+\widehat{p}_{4}+\widehat{p}_{8}$ (the updated probability that $f_{1}$ yields $z_{2}$ ), and the efficient level of care for $f_{2}$ is a function of $\alpha_{2}$ and the sum $\widehat{p}_{2}+\widehat{p}_{4}+\widehat{p}_{6}$ (the updated probability that $f_{2}$ yields $z_{2}$ ). Without Act Independence these sums are only partially identified (because $\widehat{p}_{6}$ and $\widehat{p}_{8}$ are not separately identified), creating ambiguity with respect to the updated risks of both activities. As a result, the court cannot stipulate precise new due care standards for either activity. The best the court can do is specify lower and upper bounds. Given these bounds, and given that the victim's claims make the world aware of $z_{3}$ (and its links to $f_{1}$ and $f_{2}$ ), outsiders can deduce $\alpha_{1}, \alpha_{2}$, and $\delta$; however, the best they can do is infer bounds on $\widehat{h}_{1}\left(x_{1}\right)$ and $\widehat{h}_{2}\left(x_{2}\right)$.

As before, the ambiguity can be resolved if the parties learn more about $\widehat{p}$. For instance, if the parties learn not only $\delta$ and $\gamma$ but also either $\widehat{p}_{3}+\widehat{p}_{4}+\widehat{p}_{8}$ or $\widehat{p}_{2}+\widehat{p}_{4}+\widehat{p}_{6}$, this is sufficient to separately identify $\widehat{p}_{5}, \widehat{p}_{6}, \widehat{p}_{7}$, and $\widehat{p}_{8}$. With this, the court can stipulate precise new due care standards for $f_{1}$ and $f_{2}$, from which outsiders can learn $\widehat{h}_{1}\left(x_{2}\right)$ and $\widehat{h}_{2}\left(x_{2}\right)$.

In summary, without Act Independence, Reverse Bayesianism only partially identifies $\widehat{p}$. This does not create an issue in the case of a new act - the court's information is sufficiently precise to stipulate a due care standard for each activity. In the case of a new link or consequence, however, it creates ambiguity with respect to the updated risk of one or both activities, leading to imprecise due care standards. In short, we might say that, without Act Independence, negligence achieves only "boundedly" optimal tort deterrence. That said,

\footnotetext{
${ }^{27}$ See the proof of Proposition 5.3 in the Appendix.
} 
negligence still has a partial advantage over strict liability. What's more, the ambiguity in any case can be resolved if the parties learn more about $\widehat{p}$. In other words, the more the parties learn about the updated probability of harm, the less important is Act Independence.

\section{General Model}

In this section we extend the examples from the previous section to a more general model with $m$ acts and $n$ consequences. We also relax the shape restrictions on the care cost and expected harm reduction functions and assume only that each is convex.

Let $F=\left\{f_{1}, \ldots, f_{m}\right\}$ be the set of activities and $Z=\left\{z_{1}, \ldots, z_{n}\right\}$ be the set of harms, where $0 \leq z_{1}<z_{2}<\cdots<z_{n}$. For each activity $f_{i}$, the cost of taking care $x_{i} \geq 0$ is $c\left(x_{i}\right)$, where $c(0)=0, c^{\prime}\left(x_{i}\right)>0$, and $c^{\prime \prime}\left(x_{i}\right)>0$ for all $x_{i} \geq 0$. Activity $f_{i}$ 's expected harm is $h_{i}\left(x_{i}\right) \equiv \sum_{j=1}^{n} \pi_{i j} z_{j} \tau\left(x_{i}\right)$, where (i) $\pi_{i j}$ is the probability that $f_{i}$ causes $z_{j}$ and (ii) $\tau\left(x_{i}\right) \in(0,1], \tau(0)=1, \tau^{\prime}\left(x_{i}\right)<0$, and $\tau^{\prime \prime}\left(x_{i}\right) \geq 0$ for all $x_{i} \geq 0 .{ }^{28}$

Given $F$ and $Z$, the conceivable state space is $Z^{F}$, where each state $s \in Z^{F}$ is a vector of length $m$, the $i$ th element of which, $s^{i}$, is the harm $z_{j} \in Z$ caused by activity $f_{i} \in F$ in that state. The feasible state space is $S \equiv Z^{F} \backslash N$, where $N \subset Z^{F}$ is the set of null states. Each state in $N$ is induced by a nullified link between an activity $f_{i}$ and a harm $z_{j}$.

Let $p$ represent the parties' common beliefs on $Z^{F}$. The support set of $p$ is $S$. That is, $p(s)>0$ for all $s \in S$ and $p(s)=0$ for all $s \in N$.

Given $S$ and $p$, the efficient levels of care are $\widetilde{x}_{i}=\xi^{-1}\left(\sum_{j=1}^{n} \pi_{i j} z_{j}\right), i=1, \ldots, m$, where (i) $\xi^{-1}$ denotes the inverse of $\xi\left(x_{i}\right) \equiv-c^{\prime}\left(x_{i}\right) / \tau^{\prime}\left(x_{i}\right)$ and (ii) $\pi_{i j}=\sum_{s \in S: s^{i}=z_{j}} p(s)$. Under negligence, the court stipulates $\bar{x}_{i}=\widetilde{x}_{i}$ as the due care standard for each activity $f_{i}$.

\subsection{New Link}

Assume $S \subset Z^{F}$. Suppose the parties discover a new link from $f_{l}$ to $z_{k}$ for some $l \in\{1, \ldots, m\}$ and $k \in\{1, \ldots, n\}$. Let $\widehat{S}$ denote the expanded feasible state space and $\widehat{p}$ denote the parties' updated beliefs on $\widehat{S}$. Observe that $\widehat{S}=S \cup \Delta$, where $\Delta=A_{l}\left(z_{k}\right)$ is the newly discovered event that $f_{l}$ yields $z_{k}$. Intuitively, $\Delta$ is a copy of any one of the act events $A_{l}\left(z_{j}\right)$ in $S$, except that $f_{l}$ yields $z_{k}$ (instead of $z_{j}$ ) in every state in $\Delta$. By virtue of a tort litigation, the parties learn that $f_{l}$ yields $z_{k}$ with probability $\delta>0$. By defintion, $\delta=\widehat{p}(\Delta)$.

\footnotetext{
${ }^{28}$ For example, we could have $\tau\left(x_{i}\right)=e^{-x_{i}}$.
} 
For each state $s \in \Delta$, let $L(s) \equiv\left\{t \in S: t^{i}=s^{i}, \forall i \neq l\right\}$ denote the event in $S$ that corresponds to the state $s \in \Delta$. In other words, $L(s)$ comprises the states in $S$ in which every activity (other than $f_{l}$ ) yields the same consequence that it yields in state $s \in \Delta$.

By Reverse Bayesianism, the relative likelihoods of the states in $S$ are preserved: $p(s) / p(t)=$ $\widehat{p}(s) / \widehat{p}(t)$ for all $s, t \in S$. By Act Independence, the probability of each state in $\widehat{S}$ equals the product of the probabilities of its constituent act events in $\widehat{S}: \widehat{p}(s)=\prod_{i=1}^{m} \widehat{p}\left(A_{i}\left(s^{i}\right)\right)$ for all $s=\left(s^{1}, \ldots, s^{m}\right) \in \widehat{S}$. Given $\widehat{S}$ and $\widehat{p}$, the efficient levels of care are $\widehat{\widetilde{x}}_{i}=\xi^{-1}\left(\sum_{j=1}^{n} \widehat{\pi}_{i j} z_{j}\right)$, $i=1, \ldots, m$, where $\widehat{\pi}_{i j}=\sum_{s \in \widehat{S}: s^{i}=z_{j}} \widehat{p}(s)$. It follows that:

Proposition 6.1 Assume Reverse Bayesianism and Act Independence. If the parties discover a new link from $f_{l}$ to $z_{k}$, then:

(a) $\widehat{p}(s)=(1-\delta) p(s)$ for all $s \in S$.

(b) $\widehat{p}(s)=\delta p(L(s))$ for all $s \in \Delta$.

(c) $\widehat{\widetilde{x}}_{l}=\xi^{-1}\left(\sum_{j=1}^{n}(1-\delta) \pi_{l j} z_{j}+\delta z_{k}\right)$.

(d) $\widehat{\widetilde{x}}_{i}=\widetilde{x}_{i}$ for all $i \neq l$.

Because activity $f_{l}$ is newly linked to harm $z_{k}$, the due care standard for $f_{l}$ changes. If $z_{k}$ is less than the activity's prior expected harm, the standard is reduced. Otherwise it is increased. The standard is unchanged only in the knife-edge case where the newly-linked harm exactly equals the activity's prior expected harm. This is stated formally below.

Corollary 6.1 The due care standard $\widehat{\widetilde{x}}_{l}$ increases (resp. decreases) - i.e., $\widehat{\widetilde{x}}_{l}>\widetilde{x}_{l}$ (resp. $\widehat{\widetilde{x}}_{l}<\widetilde{x}_{l}$ ) -if and only if $z_{k}>\sum_{j=1}^{n} \pi_{l j} z_{j}$, (resp. $z_{k}<\sum_{j=1}^{n} \pi_{l j} z_{j}$ ).

Under negligence, the court stipulates $\widehat{\bar{x}}_{l}=\widehat{\widetilde{x}}_{l}$ as the new due care standard for $f_{l}$ and holds the injurer liable to pay damages of $z_{k}$ if $\widehat{\bar{x}}_{l}>\bar{x}_{l}$. This, along with the victim's claim, makes outsiders aware that $f_{l}$ can yield $z_{k}$. Moreover, they can deduce $\delta$ from $\widehat{\bar{x}}_{l}{ }^{29}$

Proposition 6.2 In the case of a new link from $f_{l}$ to $z_{k}, \delta=\frac{c^{\prime}\left(\widehat{\bar{x}}_{l}\right)+\sum_{j=1}^{n} \pi_{l j} z_{j} \tau^{\prime}\left(\widehat{\bar{x}}_{l}\right)}{\sum_{j=1}^{n} \pi_{l j} z_{j} \tau^{\prime}\left(\widehat{x}_{l}\right)-z_{k} \tau^{\prime}\left(\widehat{x}_{l}\right)}$.

\footnotetext{
${ }^{29}$ The formula in Proposition 6.2 is not necessarily as complex as it seems. For instance, $\delta=2 \widehat{\bar{x}}_{l} / z_{k}$ in the example from Section 5.1.
} 
As a result, outsiders can learn $\widehat{p}$ and $\widehat{h}_{l}\left(x_{l}\right)=\sum_{j=1}^{n}\left[(1-\delta) \pi_{i j} z_{j}+\delta z_{k}\right] \tau\left(x_{l}\right)$. This is the information that other injurers need to take efficient care.

Under strict liability, the court simply holds the injurer liable to pay damages of $z_{k}$. This makes outsiders aware that $f_{l}$ can yield $z_{k}$, but they cannot deduce $\delta$ or learn $\widehat{p}$ or $\widehat{h}_{l}\left(x_{l}\right)$. Strict liability does not reveal sufficient information for other injurers to take efficient care.

\subsection{New Act}

Assume $S \subseteq Z^{F}$. Suppose the parties discover a new activity, $f_{m+1}$. Again, let $\widehat{S}$ denote the expanded feasible state space and $\widehat{p}$ denote the parties' updated beliefs on $\widehat{S}$. Observe that $\widehat{S}=\bigcup_{j=1}^{n} \Delta_{j}$, where $\Delta_{j}=A_{m+1}\left(z_{j}\right)$ is the newly discovered event that $f_{m+1}$ yields $z_{j}$. Intuitively, each $\Delta_{j}$ is an augmented copy of $S$ in which $f_{m+1}$ yields $z_{j}$ in every state. By virtue of a tort litigation, the parties learn that $f_{m+1}$ yields $z_{j}$ with probability $\delta_{j}>0$ for all $j=1, \ldots, n .^{30}$ Note that $\delta_{j}=\widehat{p}\left(\Delta_{j}\right)$ and $\sum_{j=1}^{n} \delta_{j}=1$.

For each state $s \in S$, let $E(s) \equiv\left\{t \in \widehat{S}: t^{i}=s^{i}, \forall i \neq m+1\right\}$ denote the event in $\widehat{S}$ that corresponds to the state $s \in S$. In other words, $E(s)$ comprises the states in $\widehat{S}$ in which every act (other than $f_{m+1}$ ) yields the same consequence that it yields in state $s \in S$. Observe that $\widehat{S}=\bigcup_{s \in S} E(s)$, where $E(s)$ comprises $n$ states, one in which $f_{m+1}$ yields $z_{1}$, one in which $f_{m+1}$ yields $z_{2}$, and so forth. Index the states in each $E(s)$ by $j=1, \ldots, n$, such that $s_{j} \in E(s)$ is the state in $E(s)$ in which $f_{m+1}$ yields $z_{j}$. The connection between the sets of events $\{E(s): s \in S\}$ and $\left\{\Delta_{j}: j=1, \ldots, n\right\}$, both of which partition $\widehat{S}$, is that $\Delta_{j}$ collects the $j$ th state from each $E(s)$.

By Reverse Bayesianism, $p(s) / p(t)=\widehat{p}(E(s)) / \widehat{p}(E(t))$ for all $s, t \in S$. By Act Independence, $\widehat{p}(s)=\prod_{i=1}^{m+1} \widehat{p}\left(A_{i}\left(s^{i}\right)\right)$ for all $s=\left(s^{1}, \ldots, s^{m+1}\right) \in \widehat{S}$. Given $\widehat{S}$ and $\widehat{p}$, the efficient levels of care are $\widehat{\widetilde{x}}_{i}=\xi^{-1}\left(\sum_{j=1}^{n} \widehat{\pi}_{i j} z_{j}\right), i=1, \ldots, m+1, \widehat{\pi}_{i j}=\sum_{s \in \widehat{S}: s^{i}=z_{j}} \widehat{p}(s)$. It follows that:

Proposition 6.3 Assume Act Independence and Reverse Bayesianism. If the parties discover a new act $f_{m+1}$, then:

(a) For all $s \in S$ and corresponding $E(s) \subset \widehat{S}, \widehat{p}\left(s_{j}\right)=\delta_{j} p(s) \forall s_{j} \in E(s), j=1, \ldots, n$.

(b) $\widehat{\widetilde{x}}_{i}=\widetilde{x}_{i}$ for all $i \neq m+1$.

(c) $\widehat{\widetilde{x}}_{m+1}=\xi^{-1}\left(\sum_{j=1}^{n} \delta_{j} z_{j}\right)$.

\footnotetext{
${ }^{30}$ Assuming $\delta_{j}>0$ for all $j$ is without loss of generality. We can deal with the case where $\delta_{j}=0$ for some $j$ by assuming $\delta_{j}>0$ for the first $k<n$ and changing $n$ to $k$ as necessary in the statements below.
} 
Under negligence, the court stipulates $\widehat{\bar{x}}_{m+1}=\widehat{\widetilde{x}}_{m+1}$ as the due care standard for the new activity $f_{m+1}$ and holds the injurer liable. (The due care standards for $f_{1}, \ldots, f_{m}$ are unchanged.) This makes outsiders aware of $f_{m+1}$ (and that it is risky). Although they cannot separately deduce each $\delta_{j}$ from $\widehat{\bar{x}}_{m+1}$, they nevertheless can infer $\widehat{h}_{m+1}\left(x_{m+1}\right)$ from $\widehat{\bar{x}}_{m+1} \cdot{ }^{31}$

Proposition 6.4 In the case of a new act $f_{m+1}, \widehat{h}_{m+1}\left(x_{m+1}\right)=-\frac{c^{\prime}\left(\widehat{\bar{x}}_{m+1}\right)}{\tau^{\prime}\left(\bar{x}_{m+1}\right)} \tau\left(x_{m+1}\right)$.

Thus, negligence reveals sufficient information for others to take efficient care. Under strict liability, by contrast, the court simply holds the injurer liable to pay damages to the victim. This makes outsiders aware of $f_{m+1}$ (and that it is risky), but they do not learn $\widehat{h}_{m+1}\left(x_{m+1}\right)$. Again, strict liability does not reveal enough information to induce efficient care.

\subsection{New Consequence}

Assume $S \subseteq Z^{F}$. Suppose the parties discover a new consequence, $z_{n+1}$. Once again, let $\widehat{S}$ denote the expanded feasible state space and $\widehat{p}$ denote the parties' updated beliefs on $\widehat{S}$. Observe that $\widehat{S}=S \cup \Delta$, where $\Delta=\bigcup_{i=1}^{m} A_{i}\left(z_{n+1}\right)$ is the union of the newly discovered events that $f_{i}$ yields $z_{n+1}$ for all $i=1, \ldots, m$. By virtue of a tort litigation, the parties learn that $f_{i}$ yields $z_{n+1}$ with probability $\alpha_{i}>0$ for all $i=1, \ldots, m .{ }^{32}$ That is, $\alpha_{i}=\widehat{p}\left(A_{i}\left(z_{n+1}\right)\right)$. Let $\delta=\widehat{p}(\Delta)$.

For each state $s \in \Delta$, let $I(s) \equiv\left\{i \in\{1, \ldots, m\}: s^{i}=z_{n+1}\right\}$ denote the indices of the acts that yield $z_{n+1}$ in that state of the world, and let $\bar{I}(s) \equiv\left\{i \in\{1, \ldots, m\}: s^{i} \neq z_{n+1}\right\}$ denote the indices of the acts that do not yield $z_{n+1}$ in that state of the world. In addition, for each $s \in \Delta$, let $C(s) \equiv\left\{t \in S: t^{i}=s^{i}, \forall i \in \bar{I}(s)\right\}$ denote the event in $S$ that corresponds to $s \in \Delta$ on $\bar{I}(s)$. In other words, $C(s)$ comprises the states in $S$ in which every act (other than the acts that yield $z_{n+1}$ ) yields the same consequence that it yields in state $s \in \Delta$.

By Reverse Bayesianism, $p(s) / p(t)=\widehat{p}(s) / \widehat{p}(t)$ for all $s, t \in S$. By Act Independence, $\widehat{p}(s)=\prod_{i=1}^{m} \widehat{p}\left(A_{i}\left(s^{i}\right)\right)$ for all $s=\left(s^{1}, \ldots, s^{m}\right) \in \widehat{S}$. In particular, the probability of the event that no activity yields $z_{n+1}$ is $1-\delta=\prod_{i=1}^{m}\left(1-\alpha_{i}\right)$. It follows that:

Proposition 6.5 Assume Reverse Bayesianism and Act Independence. If the parties discover a new consequence $z_{n+1}$, then:

\footnotetext{
${ }^{31}$ Note, however, that if each $z_{j}$ is a different type of harm that requires a different type of care, then the court would stipulate a different due care standard $\widehat{\bar{x}}_{m+1, j}$ with respect to each $z_{j}$, in which case outsiders could separately deduce each $\delta_{j}$.

${ }^{32}$ Assuming $\alpha_{i}>0$ for all $i$ is without loss of generality. We can deal with the case where $\alpha_{i}=0$ for some $i$ by assuming $\alpha_{i}>0$ for the first $l<m$ and changing $m$ to $l$ as necessary in the statements below.
} 
(a) $\widehat{p}(s)=\left(\prod_{i=1}^{m}\left(1-\alpha_{i}\right)\right) p(s)=(1-\delta) p(s)$ for all $s \in S$.

(b) $\widehat{p}(s)=\left(\prod_{i \in I(s)} \alpha_{i}\right)\left(\prod_{i \in \bar{I}(s)}\left(1-\alpha_{i}\right)\right) p(C(s))$ for all $s \in \Delta$ such that $I(s) \subset\{1, \ldots, m\}$.

(c) $\widehat{p}(s)=\prod_{i=1}^{m} \alpha_{i}$ for the $s \in \Delta$ such that $I(s)=\{1, \ldots, m\}$.

Part (a) is dictated by Reverse Bayesianism. The relative likelihoods of the states in $S$ are preserved. Parts (b) and (c) are dictated by Act Independence. Part (c) is a direct implication. The probability of the state in which activity yields $z_{n+1}$ is $\prod_{i=1}^{m} \alpha_{i}$. Part (b) says that the probabilities of the other states in $\widehat{S}$ are proportionate to the probabilities of their corresponding events in $S$.

Given $\widehat{S}$ and $\widehat{p}$, the efficient levels of care are $\widehat{\widetilde{x}}_{i}=\xi^{-1}\left(\sum_{j=1}^{n+1} \widehat{\pi}_{i j} z_{j}\right), i=1, \ldots, m$, where $\widehat{\pi}_{i j}=\sum_{s \in \widehat{S}: s^{i}=z_{j}} \widehat{p}(s)$. Specifically:

Proposition 6.6 Assume Reverse Bayesianism and Act Independence. If the parties discover a new consequence $z_{n+1}$, then $\widehat{\widetilde{x}}_{i}=\xi^{-1}\left(\sum_{j=1}^{n}\left(1-\alpha_{i}\right) \pi_{i j} z_{j}+\alpha_{i} z_{n+1}\right), i=1, \ldots, m$.

It follows that the due care standard for activity $f_{i}, i=1, \ldots, m$, is unchanged after the discovery of $z_{n+1}$ if and only if $z_{n+1}$ equals the activity's prior expected harm.

Corollary 6.2 The due care standard $\widehat{\widetilde{x}}_{i}, i=1, \ldots, m$, increases (resp. decreases)-i.e., $\widehat{\widetilde{x}}_{i}>\widetilde{x}_{i}\left(\operatorname{resp} . \widehat{\widetilde{x}}_{i}<\widetilde{x}_{i}\right)$-if and only if $z_{n+1}>\sum_{j=1}^{n} \pi_{i j} z_{j}$, (resp. $\left.z_{n+1}<\sum_{j=1}^{n} \pi_{i j} z_{j}\right)$.

Thus, the discovery of $z_{n+1}$ necessitates the stipulation of new due care standards for each activity $f_{i}$ such that $z_{n+1} \neq \sum_{j=1}^{n} \pi_{i j} z_{j}$.

Under negligence, the court stipulates $\widehat{\bar{x}}_{i}=\widehat{\widetilde{x}}_{i}, i=1, \ldots, m$, as the new due care standards for $f_{1}, \ldots, f_{m}$ and holds the injurer liable to pay damages of $z_{n+1}$ to the victim with respect to each activity $f_{i}$ such that $\widehat{\bar{x}}_{i}>\bar{x}_{i}$. This, along with the victim's claims, makes outsiders aware of $z_{n+1}$ (and that it is linked to $f_{1}, \ldots, f_{m}$ ). Moreover, they can deduce $\alpha_{1}, \ldots, \alpha_{m}$ from $\widehat{\bar{x}}_{1}, \ldots, \widehat{\bar{x}}_{m}$.

Proposition 6.7 In the case of a new consequence $z_{n+1}, \alpha_{i}=\frac{c^{\prime}\left(\widehat{\bar{x}}_{i}\right)+\sum_{j=1}^{n} \pi_{i j} z_{j} \tau^{\prime}\left(\overline{\bar{x}}_{i}\right)}{\sum_{j=1}^{n} \pi_{i j} z_{j} \tau^{\prime}\left(\widehat{\bar{x}}_{i}\right)-z_{n+1} \tau^{\prime}\left(\widehat{\bar{x}}_{i}\right)}$ for all $i=1, \ldots, m$.

As a result, outsiders can learn $\widehat{p}$ and $\widehat{h}_{1}\left(x_{1}\right), \ldots, \widehat{h}_{m}\left(x_{m}\right)$. This is sufficient information for other injurers to take efficient care.

As before, strict liability reveals too little information. It makes outsiders aware of $z_{n+1}$ (and that it is linked to $f_{1}, \ldots, f_{m}$ ), but they cannot deduce $\alpha_{1}, \ldots, \alpha_{m}$, and hence cannot learn $\widehat{p}$ and $\widehat{h}_{1}\left(x_{1}\right), \ldots, \widehat{h}_{m}\left(x_{m}\right)$. 


\section{Related Literature and Our Contributions}

To our knowledge, this paper is the first to incorporate unawareness into the economic analysis of tort law. As such, we contribute to the tort law and economics literature and to the unawareness literature, both of which are too vast to review here. ${ }^{33}$

A handful of papers apply unawareness models to study other legal topics. The bulk of these focus on contracts. For example, Board and Chung (2011) argue that asymmetric unawareness provides a justification for the contra proferentem doctrine of contract interpretation, which provides that ambiguous terms in a contract should be construed against the drafter; Zhao (2011) argues that unawareness may explain the existence of force majeure clauses in contracts; Grant et al. (2012) study aspects of differential awareness that give rise to contractual disputes; Filiz-Ozbay (2012) posits asymmetric awareness as a reason for the incompleteness of contracts; von Thadden and Zhao $(2012,2014)$ study the properties of optimal contracts under moral hazard when the agent may be partially unaware of her action space; and Auster (2013) introduces asymmetric unawareness into the canonical moral hazard model and analyzes the properties of the optimal contract.

Within the law and economics literature, the papers closest to ours include Teitelbaum (2007), Chakravarty and Kelsey (2017), and Franzoni (2017), which explore the implications of ambiguity for tort law. ${ }^{34}$ Although ambiguity and unawareness are distinct phenomena, both are types of uncertainty that the standard accident model does not admit. Hence, we share a common enterprise with the papers on tort law and ambiguity. We enrich the standard accident model to allow the parties to face not just risk but rather a more profound and realistic type of uncertainty, and we explore the implications of such uncertainty for the debate over tort liability rules.

\footnotetext{
${ }^{33}$ The tort law and economics literature was pioneered by Brown (1973). Other early contributions include Diamond (1974a,b), Green (1976), and Shavell (1980). Surveys of this literature include Shavell (2007), Schäfer and Müller-Langer (2009), and more recently Arlen (2017). The unawareness literature was pioneered by Fagin and Halpern (1988). Other early contributions include Modica and Rustichini (1994, 1999), Dekel et al. (1998), Halpern (2001), Heifetz et al. (2006), and Halpern and Rêgo (2008). Surveys of this literature include Schipper (2014) (which offers a "gentle introduction") and Schipper (2015) (which provides an extended review). Karni and Vierø (2013) were among the first to use the choice-theoretic approach (i.e., the state-space approach) to modeling unawareness. Karni and Vierø (2013, 2017) and Dominiak and Tserenjigmid (2022) survey the papers that take this approach.

${ }^{34}$ Also related are the papers that explore the implications of risk aversion for tort law. In the seminal paper on the topic, Shavell (1982) shows that strict liability is superior when the injurer is risk neutral and the victim is risk averse, while negligence is superior in the opposite case. Franzoni (2017, n. 10) reviews other papers on optimal tort liability rules under risk aversion and related contributions.
} 
We also share connections with Currie and MacLeod (2014), who develop an alternative to the standard accident model that makes use of state-space representations, dubbed "Savage Tables," to model the decision problems faced by an injurer (who is fully aware of the state space) under different liability rules. They apply their model to argue, inter alia, that negligence provides better incentives than strict liability in the case of the Good Samaritan.

Ott and Schäfer (1997) study how the due care standard in negligence develops when the court starts with no information about the efficient level of care and relies on information provided by the parties in litigation. In their model, an efficient standard evolves over time as a result of a learning process based on the information acquired by the court from litigants. In a similar vein, Feess and Wohlschlegel (2006) compare negligence and strict liability when some injurers have better information than others and the court about the efficient level of care and the court does not know which injurers are informed and uninformed. They show that, under certain conditions, the court can learn the efficient level of care by imperfectly observing the injurer's level of care in a large number of cases, and that under negligence (but not strict liability) the uninformed injurers can in turn learn the efficient level of care by observing the court's due care standard.

Like Ott and Schäfer (1997) we study the evolution of the negligence due care standard in response to knowledge generated by litigants, and like Feess and Wohlschlegel (2006) we argue that negligence has an advantage over strict liability in terms of knowledge transmission. Our motivation and analysis fundamentally differ from theirs, however, as we consider a world with symmetric unawareness whereas they consider a (fully aware) world with asymmetric information. Moreover, we explicitly model the process of belief revision in the wake of growing awareness and of knowledge transmission through the due care standard. In contrast, Ott and Schäfer (1997) derive transition probabilities from one standard to another and Feess and Wohlschlegel (2006) derive steady-state beliefs in a rational expectations equilibrium.

We also contribute to the relatively nascent but rapidly growing behavioral law and economics literature. Sunstein (1997), Jolls et al. (1998), and Korobkin and Ulen (2000) were early calls for the modification of standard law and economics models to reflect advances in behavioral economics and decision theory. Sunstein (2000) and Parisi and Smith (2005) are edited volumes that collect early papers in the literature. Zamir and Teichman (2014) and Teitelbaum and Zeiler (2018) are more recent volumes. Halbersberg and Guttel (2014) and Luppi and Parisi (2018) provide surveys of behavioral models of tort law. 


\section{Discussion}

This paper extends the economic analysis of tort law to incorporate unawareness. We compare and contrast negligence and strict liability in a unilateral accident model with unawareness and growing awareness, and find that negligence has a key advantage - the due care standard serves as a knowledge transmission mechanism. Under either tort liability rule, a suit involving a newly discovered act, consequence, or link makes the world aware of a new possibility of harm. But only negligence, through the stipulation of new due care standards, spreads awareness about the updated probability of harm. ${ }^{35}$

The negligence due care standard is like a public good. The social benefit of spreading awareness about the updated probability of harm is that potential injurers and victims need not expend additional resources to develop this knowledge. This wastefully duplicative effort would be necessary to achieve optimal deterrence under strict liability. In a sense, negligence is akin to patents; both carry social costs (negligence is more costly to administer; patents create monopolies and deadweight loss), yet both provide social benefits in terms of knowledge transmission. One should bear in mind, however, that we do not purport to undertake a full welfare analysis. We do not claim that negligence is superior to strict liability in all circumstances. Rather, we claim that negligence is more robust to unawareness.

To model unawareness and growing awareness, we adopt the Reverse Bayesian approach of Karni and Vierø (2013). This model has (at least) two attractive features. The first is transparency. Karni and Vierø (2013) provide an axiomatic foundation for the model, and so one can judge the theory by the axioms. ${ }^{36}$ The second is its accessibility. The model is built upon a familiar choice-theoretic framework (expected utility theory), and the upshot is a belief revision theory that mirrors the process of Bayesian updating. Becker et al. (2022) present experimental evidence in support of Reverse Bayesianism.

At the same time, the Reverse Bayesian model has its shortcomings. For instance, Chambers and Hayashi (2018) criticize its empirical content from a revealed preference perspective. They show that, in the case of a new consequence, the model does not make singular predictions about observable choices over feasible acts. A second shortcoming of the model is

\footnotetext{
${ }^{35}$ Our argument can be extended to bilateral accidents. In this case, it would suggest that negligence with a defense of contributory negligence (which is efficient as long as both due care standards are set correctly) is superior to simple negligence (and to strict liability with a defense of contributory negligence) because the court sets due care standards for both agents and as a result more information is released.

${ }^{36}$ The key axioms of the model are the "consistency" axioms, which essentially require that preferences conditional on the original state of awareness are not altered by growing awareness.
} 
that it assumes a naive or myopic unawareness - people are unaware that they are unaware. A sophisticated unawareness, where people are aware that they are unaware, may be more realistic. In response, Karni and Vierø (2017) extend their model to the case of sophisticated unawareness. The end result is a generalization that maintains the flavor of Reverse Bayesianism and nests the naive model as a special case.

The pros and cons of the model aside, one might question the importance of our results in a world with safety regulation in addition to tort liability. In such a world, one could argue, there are regulators and other non-court actors who can spread awareness about newly discovered risks. While this may be correct, it is orthogonal to our inquiry. We are contributing to the negligence versus strict liability debate. We therefore consider a world where the tort system is the only mechanism for regulating risky activities, and we compare and contrast the two primary tort liability rules. If one were to consider a world with safety regulation in addition to tort law, one would have to take into account the liability versus regulation debate (e.g., Shavell, 1984a,b; Posner, 2010), and conclude that regulation is the more efficient method of social control, before one could assert that the possibility of safety regulation renders moot the debate over tort liability rules.

The importance of unawareness and growing awareness - via technological progress, scientific discovery, or otherwise - plainly extends beyond the case of unilateral accidents with fixed activity levels. Natural extensions of this paper, therefore, would entail introducing unawareness into other accident settings. In addition, future research could examine the implications of unawareness for the economic analysis of other areas of law such as contract remedies and criminal law or other topics such as litigation and settlement.

\section{Appendix}

Proof of Proposition 5.1 By Reverse Bayesianism, the definition of $\delta$, and $\widehat{p}_{1}+\widehat{p}_{2}+$ $\widehat{p}_{3}+\widehat{p}_{4}=1$, we have $\widehat{p}_{2}=\frac{p_{2}}{p_{1}} \widehat{p}_{1}$ and $\widehat{p}_{1}+\widehat{p}_{2}=1-\delta$. Substituting the first equation into the second, we have $\widehat{p}_{1}+\frac{p_{2}}{p_{1}} \widehat{p}_{1}=1-\delta$, which implies

$$
\widehat{p}_{1}=\frac{(1-\delta) p_{1}}{p_{1}+p_{2}}=(1-\delta) p_{1}
$$

where the last equality follows from $p_{1}+p_{2}=1$. It follows that

$$
\widehat{p}_{2}=\frac{p_{2}}{p_{1}}(1-\delta) p_{1}=(1-\delta) p_{2}
$$


By Act Independence and the definition of $\delta$, we have $\widehat{p}_{3}=\delta\left(\widehat{p}_{1}+\widehat{p}_{3}\right)$ and $\widehat{p}_{4}=\delta\left(\widehat{p}_{2}+\widehat{p}_{4}\right)$, which imply $\widehat{p}_{3}=\frac{\delta}{1-\delta} \widehat{p}_{1}$ and $\widehat{p}_{4}=\frac{\delta}{1-\delta} \widehat{p}_{2}$. It follows that

$$
\widehat{p}_{3}=\frac{\delta}{1-\delta}(1-\delta) p_{1}=\delta p_{1} \quad \text { and } \quad \widehat{p}_{4}=\frac{\delta}{1-\delta}(1-\delta) p_{2}=\delta p_{2}
$$

Proof of Proposition 5.2 Reverse Bayesianism implies the following conditions:

$$
p_{2}\left(\widehat{p}_{1}+\widehat{p}_{5}\right)=p_{1}\left(\widehat{p}_{2}+\widehat{p}_{6}\right), \quad p_{3}\left(\widehat{p}_{1}+\widehat{p}_{5}\right)=p_{1}\left(\widehat{p}_{3}+\widehat{p}_{7}\right), \quad \text { and } \quad p_{4}\left(\widehat{p}_{1}+\widehat{p}_{5}\right)=p_{1}\left(\widehat{p}_{4}+\widehat{p}_{8}\right)
$$

Summing the left- and right-hand sides, and adding $p_{1}\left(\widehat{p}_{1}+\widehat{p}_{5}\right)$ to each side, yields

$$
\left(p_{1}+p_{2}+p_{3}+p_{4}\right)\left(\widehat{p}_{1}+\widehat{p}_{5}\right)=\left(\widehat{p}_{1}+\cdots+\widehat{p}_{8}\right) p_{1}
$$

Because $p_{1}+p_{2}+p_{3}+p_{4}=1$ and $\widehat{p}_{1}+\cdots+\widehat{p}_{8}=1$, we have $\widehat{p}_{1}+\widehat{p}_{5}=p_{1}$. Substituting this back into the Reverse Bayesian conditions yields

$$
\widehat{p}_{1}+\widehat{p}_{5}=p_{1}, \quad \widehat{p}_{2}+\widehat{p}_{6}=p_{2}, \quad \widehat{p}_{3}+\widehat{p}_{7}=p_{3}, \quad \text { and } \quad \widehat{p}_{4}+\widehat{p}_{8}=p_{4}
$$

By Act Independence and the definition of $\delta$, we have

$$
\widehat{p}_{5}=\left(\widehat{p}_{1}+\widehat{p}_{5}\right) \delta, \quad \widehat{p}_{6}=\left(\widehat{p}_{2}+\widehat{p}_{6}\right) \delta, \quad \widehat{p}_{7}=\left(\widehat{p}_{3}+\widehat{p}_{7}\right) \delta, \quad \text { and } \quad \widehat{p}_{8}=\left(\widehat{p}_{4}+\widehat{p}_{8}\right) \delta .
$$

These imply

$$
\widehat{p}_{5}=\frac{\delta}{1-\delta} \widehat{p}_{1}, \quad \widehat{p}_{6}=\frac{\delta}{1-\delta} \widehat{p}_{2}, \quad \widehat{p}_{7}=\frac{\delta}{1-\delta} \widehat{p}_{3}, \quad \text { and } \quad \widehat{p}_{8}=\frac{\delta}{1-\delta} \widehat{p}_{4}
$$

It follows that

$$
\widehat{p}_{1}+\frac{\delta}{1-\delta} \widehat{p}_{1}=p_{1}, \quad \widehat{p}_{2}+\frac{\delta}{1-\delta} \widehat{p}_{2}=p_{2}, \quad \widehat{p}_{3}+\frac{\delta}{1-\delta} \widehat{p}_{3}=p_{3}, \quad \text { and } \quad \widehat{p}_{4}+\frac{\delta}{1-\delta} \widehat{p}_{4}=p_{4}
$$

These imply $\widehat{p}_{1}=(1-\delta) p_{1}, \widehat{p}_{2}=(1-\delta) p_{2}, \widehat{p}_{3}=(1-\delta) p_{3}$, and $\widehat{p}_{4}=(1-\delta) p_{4}$, which in turn imply $\widehat{p}_{5}=\delta p_{1}, \widehat{p}_{6}=\delta p_{2}, \widehat{p}_{7}=\delta p_{3}$, and $\widehat{p}_{8}=\delta p_{4}$.

Proof of Proposition 5.3 Reverse Bayesianism implies the following conditions:

$$
p_{2} \widehat{p}_{1}=p_{1} \widehat{p}_{2}, \quad p_{3} \widehat{p}_{1}=p_{1} \widehat{p}_{3}, \quad \text { and } \quad p_{4} \widehat{p}_{1}=p_{1} \widehat{p}_{4}
$$


Summing the left- and right-hand sides, and adding $p_{1} \widehat{p}_{1}$ to each side, yields

$$
\left(p_{1}+p_{2}+p_{3}+p_{4}\right) \widehat{p}_{1}=\left(\widehat{p}_{1}+\widehat{p}_{2}+\widehat{p}_{3}+\widehat{p}_{4}\right) p_{1},
$$

which implies $\widehat{p}_{1}=(1-\delta) p_{1} \cdot{ }^{37}$ Substituting this back in the Reverse Bayesian conditions yields $\widehat{p}_{2}=(1-\delta) p_{2}, \widehat{p}_{3}=(1-\delta) p_{3}$, and $\widehat{p}_{4}=(1-\delta) p_{4}$.

By Act Independence, $\widehat{p}_{5}=\left(\widehat{p}_{5}+\widehat{p}_{6}+\widehat{p}_{9}\right)\left(\widehat{p}_{1}+\widehat{p}_{3}+\widehat{p}_{5}\right)=\alpha_{1}\left(\widehat{p}_{1}+\widehat{p}_{3}+\widehat{p}_{5}\right)$. Hence,

$$
\left(1-\alpha_{1}\right) \widehat{p}_{5}=\alpha_{1}\left(\widehat{p}_{1}+\widehat{p}_{3}\right)=\alpha_{1}(1-\delta)\left(p_{1}+p_{3}\right),
$$

which implies $\widehat{p}_{5}=\alpha_{1}\left(1-\alpha_{2}\right)\left(p_{1}+p_{3}\right)$ (using $1-\delta=\left(1-\alpha_{1}\right)\left(1-\alpha_{2}\right)$ ). By similar reasoning, $\widehat{p}_{6}=\alpha_{1}\left(1-\alpha_{2}\right)\left(p_{2}+p_{4}\right), \widehat{p}_{7}=\left(1-\alpha_{1}\right) \alpha_{2}\left(p_{1}+p_{2}\right)$, and $\widehat{p}_{8}=\left(1-\alpha_{1}\right) \alpha_{2}\left(p_{3}+p_{4}\right)$. Finally, $s_{9}$ is the event that both acts yield the new consequence. By Act Independence its probability equals the product of the probabilities of its constituent act events: $\widehat{p}_{9}=\alpha_{1} \alpha_{2}$.

Proof of Proposition 6.1 Parts (a) and (b) follow from Theorem 1 of Chakravarty et al. (2022).

(c) Observe that $\sum_{j=1}^{n} \widehat{\pi}_{l j} z_{j}=\sum_{j \neq k} \widehat{\pi}_{l j} z_{j}+\delta z_{k}$. By parts (a) and (b),

$$
\sum_{j \neq k} \widehat{\pi}_{l j} z_{j}=\sum_{j \neq k}\left[\sum_{s \in \widehat{S}: s^{l}=z_{j}} \widehat{p}(s)\right] z_{j}=\sum_{j \neq k}\left[\sum_{s \in S: s^{l}=z_{j}}(1-\delta) p(s)+\sum_{s \in \Delta: s^{l}=z_{j}} \delta p(L(s))\right] z_{j} .
$$

Observe that $s^{l}=z_{k}$ for all $s \in \Delta$. It follows that, for all $j \neq k, \sum_{s \in \Delta: s^{l}=z_{j}} \delta p(L(s))=0$. Thus,

$$
\sum_{j \neq k} \widehat{\pi}_{l j} z_{j}=\sum_{j \neq k}\left[\sum_{s \in S: s^{l}=z_{j}}(1-\delta) p(s)\right] z_{j}=\sum_{j \neq k}(1-\delta) \pi_{l j} z_{j}=\sum_{j=1}^{n}(1-\delta) \pi_{l j} z_{j},
$$

where the last equality follows from $\pi_{l k}=0$. Hence, $\sum_{j=1}^{n} \widehat{\pi}_{l j} z_{j}=\sum_{j=1}^{n}(1-\delta) \pi_{l j} z_{j}+\delta z_{k}$.

(d) Take any $i \neq l$ and any $j$. By parts (a) and (b),

$$
\widehat{\pi}_{i j}=\sum_{s \in \widehat{S}: s^{i}=z_{j}} \widehat{p}(s)=\sum_{s \in S: s^{i}=z_{j}}(1-\delta) p(s)+\sum_{s \in \Delta: s^{i}=z_{j}} \delta p(L(s)) .
$$

Observe that $L(s)$ is the union of all $t \in S$ such that $t^{i}=s^{i}$ for all $i \neq l$. Thus,

$$
\sum_{s \in \Delta: s^{i}=z_{j}} p(L(s))=\sum_{t \in S: t^{i}=z_{j}} p(t) .
$$

\footnotetext{
${ }^{37}$ Note that $p_{1}+p_{2}+p_{3}+p_{4}=1$ and $\widehat{p}_{1}+\widehat{p}_{2}+\widehat{p}_{3}+\widehat{p}_{4}=1-\delta$.
} 
Hence,

$$
\widehat{\pi}_{i j}=\sum_{s \in S: s^{i}=z_{j}}(1-\delta) p(s)+\sum_{s \in S: s^{i}=z_{j}} \delta p(s)=\sum_{s \in S: s^{i}=z_{j}} p(s)=\pi_{i j} .
$$

It follows that $\widehat{\widetilde{x}}_{i}=\widetilde{x}_{i}$ for all $i \neq l$.

Proof of Corollary 6.1 By Proposition 6.1, $\xi\left(\widehat{\widetilde{x}}_{l}\right)=\sum_{j=1}^{n}(1-\delta) \pi_{l j} z_{j}+\delta z_{k}$. Observe that $\xi\left(\widetilde{x}_{l}\right)=\sum_{j=1}^{n} \pi_{l j} z_{j}$. It follows that $\xi\left(\widehat{\widetilde{x}}_{l}\right)>\xi\left(\widetilde{x}_{l}\right)$ if and only if $z_{k}>\sum_{j=1}^{n} \pi_{l j} z_{j}$. Because $\xi^{\prime}\left(x_{i}\right)>0$ for all $x_{i}$, we have $\widehat{\widetilde{x}}_{l}=\widetilde{x}_{l}$ if and only if $z_{k}=\sum_{j=1}^{n} \pi_{l j} z_{j}$. The case where $z_{k}<\sum_{j=1}^{n} \pi_{l j} z_{j}$ is similar.

Proof of Proposition 6.2 By Proposition 6.1 and $\widehat{\bar{x}}_{l}=\widehat{\widetilde{x}}_{l}$, we have $\xi\left(\widehat{\bar{x}}_{l}\right)=$ $\sum_{j=1}^{n}(1-\delta) \pi_{l j} z_{j}+\delta z_{k}$. It follows that

$$
\delta=\frac{\xi\left(\widehat{\bar{x}}_{l}\right)-\sum_{j=1}^{n} \pi_{l j} z_{j}}{z_{k}-\sum_{j=1}^{n} \pi_{l j} z_{j}}
$$

Observe that $\xi\left(\widehat{\bar{x}}_{l}\right)=-c^{\prime}\left(\widehat{\bar{x}}_{l}\right) / \tau^{\prime}\left(\widehat{\bar{x}}_{l}\right)$. Thus,

$$
\delta=\frac{c^{\prime}\left(\widehat{\bar{x}}_{l}\right)+\sum_{j=1}^{n} \pi_{l j} z_{j} \tau^{\prime}\left(\widehat{\bar{x}}_{l}\right)}{\sum_{j=1}^{n} \pi_{l j} z_{j} \tau^{\prime}\left(\widehat{\bar{x}}_{l}\right)-z_{k} \tau^{\prime}\left(\widehat{\bar{x}}_{l}\right)}
$$

Proof of Proposition 6.3 Part (a) follows from Theorem 2 of Chakravarty et al. (2022).

(b) Recall that $\{E(s): s \in S\}$ forms a partition of $\widehat{S}$. Take any $i \neq m+1$ and any $j$. By part (a),

$$
\widehat{\pi}_{i j}=\sum_{s \in \widehat{S}: s^{i}=z_{j}} \widehat{p}(s)=\sum_{s \in S: s^{i}=z_{j}}\left[\sum_{s_{l} \in E(s)} \widehat{p}\left(s_{l}\right)\right]=\sum_{s \in S: s^{i}=z_{j}}\left[\sum_{l=1}^{n} \delta_{l} p(s)\right]=\sum_{s \in S: s^{i}=z_{j}} p(s)\left[\sum_{l=1}^{n} \delta_{l}\right] .
$$

Note that $\sum_{l=1}^{n} \delta_{l}=1$. Thus, $\widehat{\pi}_{i j}=\sum_{s \in S: s^{i}=z_{j}} p(s)=\pi_{i j}$. It follows that $\widehat{\widetilde{x}}_{i}=\widetilde{x}_{i}$ for all $i \neq m+1$.

(c) By definition, $\widehat{\pi}_{m+1, j}=\delta_{j}$ for all $j=1, \ldots, n$. Hence, $\widehat{\widetilde{x}}_{m+1}=\xi^{-1}\left(\sum_{j=1}^{n} \delta_{j} z_{j}\right)$.

Proof of Proposition 6.4 Observe that $\widehat{h}_{m+1}\left(x_{m+1}\right)=\sum_{j=1}^{n} \widehat{\pi}_{m+1, j} z_{j} \tau\left(x_{m+1}\right)$ and $\widehat{\bar{x}}_{m+1}=$ $\widehat{\widetilde{x}}_{m+1}=\xi^{-1}\left(\sum_{j=1}^{n} \widehat{\pi}_{m+1, j} z_{j}\right)$. The latter implies $\xi\left(\widehat{\bar{x}}_{m+1}\right)=\sum_{j=1}^{n} \widehat{\pi}_{m+1, j} z_{j}$. Thus, $\widehat{h}_{m+1}\left(x_{m+1}\right)=$ $\xi\left(\widehat{\bar{x}}_{m+1}\right) \tau\left(x_{m+1}\right)$. Recall that $\xi\left(x_{i}\right) \equiv-c^{\prime}\left(x_{i}\right) / \tau^{\prime}\left(x_{i}\right)$. Hence, $\widehat{h}_{m+1}\left(x_{m+1}\right)=-\frac{c^{\prime}\left(\widehat{x}_{m+1}\right)}{\tau^{\prime}\left(\widehat{x}_{m+1}\right)} \tau\left(x_{m+1}\right)$. 
Proof of Proposition 6.5 This proposition follows from Theorem 3 of Chakravarty et al. (2022).

Proof of Proposition 6.6 Take any $i \in\{1, \ldots, m\}$. Observe that

$$
\widehat{\widetilde{x}}_{i}=\xi^{-1}\left(\sum_{j=1}^{n+1} \widehat{\pi}_{i j} z_{j}\right)=\xi^{-1}\left(\sum_{j=1}^{n} \widehat{\pi}_{i j} z_{j}+\alpha_{i} z_{n+1}\right) .
$$

Let $\Gamma\left(\alpha_{l}, s\right) \equiv\left(\prod_{l \in I(s)} \alpha_{l}\right)\left(\prod_{l \in \bar{I}(s)}\left(1-\alpha_{l}\right)\right)$ for all $s \in \Delta$. By Proposition 6.5,

$$
\widehat{\pi}_{i j}=\sum_{s \in \widehat{S}: s^{i}=z_{j}} \widehat{p}(s)=\sum_{s \in S: s^{i}=z_{j}} \prod_{l=1}^{m}\left(1-\alpha_{l}\right) p(s)+\sum_{s \in \Delta: s^{i}=z_{j}} \Gamma\left(\alpha_{l}, s\right) p(C(s)),
$$

for all $j \neq n+1$. Observe that

$$
\sum_{s \in S: s^{i}=z_{j}} \prod_{l=1}^{m}\left(1-\alpha_{l}\right) p(s)=\prod_{l=1}^{m}\left(1-\alpha_{l}\right) \sum_{s \in S: s^{i}=z_{j}} p(s)=(1-\delta) \pi_{i j}
$$

and that

$$
\begin{aligned}
\sum_{s \in \Delta: s^{i}=z_{j}} \Gamma\left(\alpha_{l}, s\right) p(C(s)) & =\sum_{s \in \Delta: s^{i}=z_{j}}\left(\prod_{l \in I(s)} \alpha_{l}\right)\left(\prod_{l \in \bar{I}(s)}\left(1-\alpha_{l}\right)\right) p(C(s)) \\
& =\sum_{s \in \Delta: s^{i}=z_{j}} \frac{\prod_{l \in I(s)} \alpha_{l}}{\prod_{l \in I(s)}\left(1-\alpha_{l}\right)}(1-\delta) p(C(s)),
\end{aligned}
$$

where the last equality follows because $1-\delta=\prod_{i=1}^{n}\left(1-\alpha_{i}\right)$. Hence,

$\sum_{s \in \Delta: s^{i}=z_{j}} \Gamma\left(\alpha_{l}, s\right) p(C(s))=\sum_{I \subset\{\{1, \ldots, m\} \backslash\{i\}\}} \frac{\prod_{l \in I} \alpha_{l}}{\prod_{l \in I}\left(1-\alpha_{l}\right)}(1-\delta) \pi_{i j}=\frac{1-\prod_{l \neq i}\left(1-\alpha_{l}\right)}{\prod_{l \neq i}\left(1-\alpha_{l}\right)}(1-\delta) \pi_{i j}$.

Thus,

$$
\begin{aligned}
\widehat{\pi}_{i j} & =(1-\delta) \pi_{i j}+\frac{1-\prod_{l \neq i}\left(1-\alpha_{l}\right)}{\prod_{l \neq i}\left(1-\alpha_{l}\right)}(1-\delta) \pi_{i j} \\
& =(1-\delta) \pi_{i j}\left(\frac{1}{\prod_{l \neq i}\left(1-\alpha_{l}\right)}\right)=(1-\delta) \pi_{i j}\left(\frac{1-\alpha_{i}}{1-\delta}\right)=\left(1-\alpha_{i}\right) \pi_{i j} .
\end{aligned}
$$

Substituting (A.2) back into (A.1), we have $\widehat{\widetilde{x}}_{i}=\xi^{-1}\left(\sum_{j=1}^{n}\left(1-\alpha_{i}\right) \pi_{i j} z_{j}+\alpha_{i} z_{n+1}\right)$.

Proof of Corollary 6.2 Take any $i \in\{1, \ldots, m\}$. By Proposition 6.6, we have $\xi\left(\widehat{\widetilde{x}}_{i}\right)=$ $\sum_{j=1}^{n}\left(1-\alpha_{i}\right) \pi_{i j} z_{j}+\alpha_{i} z_{n+1}$. Observe that $\xi\left(\widetilde{x}_{i}\right)=\sum_{j=1}^{n} \pi_{i j} z_{j}$. It follows that $\xi\left(\widehat{\widetilde{x}}_{i}\right)>\xi\left(\widetilde{x}_{i}\right)$ if 
and only if $z_{n+1}>\sum_{j=1}^{n} \pi_{i j} z_{j}$. Because $\xi^{\prime}\left(x_{i}\right)>0$ for all $x_{i}$, we have $\widehat{\widetilde{x}}_{i}=\widetilde{x}_{i}$ if and only if $z_{n+1}=\sum_{j=1}^{n} \pi_{i j} z_{j}$. The case where $z_{n+1}<\sum_{j=1}^{n} \pi_{i j} z_{j}$ is similar.

Proof of Proposition 6.7 Take any $i \in\{1, \ldots, m\}$. By Proposition 6.6, $\widehat{\bar{x}}_{i}=\widehat{\widetilde{x}}_{i}=$ $\xi^{-1}\left(\sum_{j=1}^{n}\left(1-\alpha_{i}\right) \pi_{i j} z_{j}+\alpha_{i} z_{n+1}\right)$, which implies $\xi\left(\widehat{\bar{x}}_{i}\right)=\sum_{j=1}^{n}\left(1-\alpha_{i}\right) \pi_{i j} z_{j}+\alpha_{i} z_{n+1}$. It follows that

$$
\alpha_{i}=\frac{\xi\left(\widehat{\bar{x}}_{i}\right)-\sum_{j=1}^{n} \pi_{i j} z_{j}}{z_{n+1}-\sum_{j=1}^{n} \pi_{i j} z_{j}} .
$$

Observe that $\xi\left(\widehat{\bar{x}}_{i}\right)=-c^{\prime}\left(\widehat{\bar{x}}_{i}\right) / \tau^{\prime}\left(\widehat{\bar{x}}_{i}\right)$. Thus,

$$
\alpha_{i}=\frac{c^{\prime}\left(\widehat{\bar{x}}_{i}\right)+\sum_{j=1}^{n} \pi_{i j} z_{j} \tau^{\prime}\left(\widehat{\bar{x}}_{i}\right)}{\sum_{j=1}^{n} \pi_{i j} z_{j} \tau^{\prime}\left(\widehat{\bar{x}}_{i}\right)-z_{n+1} \tau^{\prime}\left(\widehat{\bar{x}}_{i}\right)} .
$$

\section{References}

American Chemical Society, "All Uses of 2,4,5-T and Silvex Pesticides Banned," Chemical and Engineering News 63(12) (1985), 6.

Arlen, J., "Economics of Tort Law," in F. Parisi, ed., The Oxford Handbook of Law and Economics, Vol. 2 (Oxford: Oxford University Press, 2017), 41-95.

Auster, S., "Asymmetric Awareness and Moral Hazard," Games and Economic Behavior 82 (2013), 503-521.

Becker, C. K., T. Melkonyan, E. Proto, A. Sofianos and S. T. Trautmann, "Reverse Bayesianism: Revising Beliefs in Light of Unforeseen Events," Working Paper, Department of Economics, Finance, and Legal Studies, University of Alabama, 2022.

BoArd, O. And K.-S. Chung, "Object-Based Unawareness: Theory and Applications," Working Paper, School of Law, New York University, 2011.

Briere, K., "BSE Class Action Lawsuit Dismissed," Western Producer, March 11, 2022.

Brown, J. P., "Toward an Economic Theory of Liability," Journal of Legal Studies 2 (1973), 323-349.

Chakravarty, S. And D. Kelsey, "Ambiguity and Accident Law," Journal of Public Economic Theory 19 (2017), 97-120.

Chakravarty, S., D. Kelsey and J. Teitelbaum, "Reverse Bayesianism and Act Independence," Journal of Economic Theory 203 (2022), 105495.

Chambers, C. P. And T. Hayashi, "Reverse Bayesianism: A Comment," American Economic Journal: Microeconomics 10 (2018), 315-324. 
Chateauneuf, A., J. Eichberger and S. Grant, "Choice under Uncertainty with the Best and Worst in Mind: Neo-additive Capacities," Journal of Economic Theory 137 (2007), 538-567.

Collee, J. G. And R. Bradley, "BSE: A Decade On-Part I," The Lancet 349 (1997), 636-641.

Crepeau, R. C., NFL Football: A History of America's New National Pastime (Urbana: University of Illinois Press, 2014).

Currie, J. M. And W. B. MacLeod, "Savage Tables and Tort Law: An Alternative to the Precaution Model," University of Chicago Law Review 81 (2014), 53-82.

Dekel, E., B. L. Lipman and A. Rustichini, "Standard State-Space Models Preclude Unawareness," Econometrica 66 (1998), 159-173.

Diamond, P. A., "Accident Law and Resource Allocation," Bell Journal of Economics and Management Science 5 (1974a), 366-405.

—_, "Single Activity Accidents," Journal of Legal Studies 3 (1974b), 107-164.

Dobbs, D. B., P. T. Hayden and E. M. Bublick, The Law of Torts (St. Paul, MN: West, 2011).

Dominiak, A. And G. Tserenjigmid, "Ambiguity under Growing Unawareness," Journal of Economic Theory 199 (2022), 105256.

Dowd, A., "Ridley Settles in Canadian Mad Cow Court Cases," Reuters, February 5, 2008.

Fagin, R. And J. Y. Halpern, "Belief, Awareness, and Limited Reasoning," Artificial Intelligence 34 (1988), 39-76.

Feess, E. And A. Wohlschlegel, "Liability and Information Transmission: The Advantage of Negligence Based Rules," Economics Letters 92 (2006), 63-67.

Filiz-OzBay, E., "Incorporating Unawareness into Contract Theory," Games and Economic Behavior 76 (2012), 181-194.

Flynn, E., "What is the NFL's Concussion Protocol?," Sports Illustrated, September 16, 2016.

Franzoni, L. A., "Liability Law under Scientific Uncertainty," American Law and Economics Review 19 (2017), 327-360.

Gold, R., The Boom: How Fracking Ignited the American Energy Revolution and Changed the World (New York: Simon \& Schuster, 2014).

Grant, S. J., J. Kline And J. Quiggin, "Differential Awareness, Ambiguity, and Incomplete Contracts: A Model of Contractual Disputes," Journal of Economic Behavior and Organization 82 (2012), 494-504. 
Green, J., "On the Optimal Structure of Liability Laws," Bell Journal of Economics 7 (1976), 553-574.

Halbersberg, Y. and E. Guttel, "Behavioral Economics and Tort Law," in E. Zamir and D. Teichman, eds., The Oxford Handbook of Behavioral Economics and the Law (New York: Oxford University Press, 2014), 405-437.

HalPeRn, J. Y., "Alternative Semantics for Unawareness," Games and Economic Behavior 37 (2001), 321-339.

Halpern, J. Y. And L. C. RÊGo, "Interactive Unawareness Revisited," Games and Economic Behavior 62 (2008), 232-262.

Heifetz, A., M. Meier And B. C. Schipper, "Interactive Unawareness," Games and Economic Behavior 130 (2006), 78-94.

Henry, D., "Oil Industry Group Launches Methane Reduction Program," The Hill, December 5, 2017.

Holusha, J., "Dow Halts Fight to Sell Herbicide," New York Times, October 15, 1983.

Jolls, C., C. R. Sunstein and R. Thaler, "A Behavioral Approach to Law and Economics," Stanford Law Review 50 (1998), 1471-1550.

KARni, E. And M.-L. Vier $\varnothing$, "Reverse Bayesianism: A Choice-Based Theory of Growing Awareness," American Economic Review 103 (2013), 2790-2810.

_- "Awareness of Unawareness: A Theory of Decision Making in the Face of Ignorance," Journal of Economic Theory 168 (2017), 301-328.

Kienlen, A., "A Decade On, BSE Lawsuit May Finally Go to Trial," Alberta Express, January 30, 2017.

Klibanoff, P., M. Marinacci and S. Mukerji, "A Smooth Model of Decision Making under Ambiguity," Econometrica 73 (2005), 1849-1892.

Korobkin, R. B. And T. S. Ulen, "Law and Behavioral Science: Removing the Rationality Assumption from Law and Economics," California Law Review 88 (2000), 1051-1144.

Lindsley, C. W., "Chronic Traumatic Encephalopathy (CTE): A Brief Historical Overview and Recent Focus on NFL Players," ACS Chemical Neuroscience 8 (2017), 1629-1631.

Luppi, B. And F. PARISI, "Behavioral Models in Tort Law," in J. C. Teitelbaum and K. Zeiler, eds., Research Handbook on Behavioral Law and Economics (Northampton, MA: Edward Elgar, 2018), 221-246.

Modica, S. And A. Rustichini, "Awareness and Partitional Information Structures," Theory and Decision 27 (1994), 265-298. 
- "Unawareness and Partitional Information Structures," Games and Economic Behavior 37 (1999), 107-124.

Ott, C. And H.-B. SchÄfer, "Negligence as Untaken Precaution, Limited Information, and Efficient Standard Formation in the Civil Liability System," International Review of Law and Economics 17 (1997), 15-29.

PARISI, F. AND V. L. Smith, EDS., The Law and Economics of Irrational Behavior (Stanford, CA: Stanford University Press, 2005).

Posner, R. A., "Regulation (Agencies) versus Litigation (Courts): An Analytical Framework," in D. P. Kessler, ed., Regulation versus Litigation: Perspectives from Economics and Law (Chicago: University of Chicago Press, 2010), 11-26.

Rozenberg, J., "Sally Bercow Learns the Social Media Rules the Hard Way in McAlpine Case," The Guardian, May 24 (2013).

Savage, L. J., The Foundations of Statistics (New York: Wiley, 1954).

Schäfer, H.-B. AND F. MÜLler-Langer, "Strict Liability versus Negligence," in M. Faure, ed., Tort Law and Economics (Cheltenham: Edward Elgar, 2009), 3-45.

Schipper, B. C., "Unawareness-A Gentle Introduction to Both the Literature and the Special Issue," Mathematical Social Sciences 70 (2014), 1-9.

—_, "Awareness," in H. van Ditmarsh, J. Y. Halpern, W. van der Hock and B. Kooi, eds., Handbook of Epistemic Logic (London: College Publications, 2015), 77-146.

Schuck, P. H., Agent Orange on Trial: Mass Toxic Disasters in the Courts, Enlarged edition (Cambridge, MA: Belknap Press of Harvard University Press, 1987).

Shavell, S., "Strict Liability versus Negligence," Journal of Legal Studies 9 (1980), 1-25.

__ , "On Liability and Insurance," Bell Journal of Economics 13 (1982), 120-132.

_ _ "Liability for Harm versus Regulation of Safety," Journal of Legal Studies 13 (1984a), $357-374$.

— , "A Model of the Optimal Use of Liability and Safety Regulation," RAND Journal of Economics 15 (1984b), 271-280. 1987).

Economic Analysis of Accident Law (Cambridge, MA: Harvard University Press, , "Liability for Accidents," in A. M. Polinsky and S. Shavell, eds., Handbook of Law and Economics, Vol. 1 (Amsterdam: North Holland, 2007), 139-182.

Stephenson, A., "Alberta Cow with Mad Cow Disease Born in 2009, After Enhanced Feed Ban Put in Place," Calgary Herald, February 18, 2015. 
Sudhakar, A., "History of Cancer, Ancient and Modern Treatment Methods," Journal of Cancer Science and Therapy 1 (2009), 1-4.

Sunstein, C. R., "Behavioral Analysis of Law," University of Chicago Law Review 64 (1997), 1175-1195.

Sunstein, C. R., ED., Behavioral Law and Economics (Cambridge: Cambridge University Press, 2000).

Talavera, J. R., "Quintana v. United Blood Services: Examining Industry Practice in Transfusion-Related AIDS Cases," Cornell Journal of Law and Public Policy 2 (1993), $475-519$.

Teitelbaum, J. C., "A Unilateral Accident Model under Ambiguity," Journal of Legal Studies 36 (2007), 431-477.

Teitelbaum, J. C. And K. Zeiler, eds., Research Handbook on Behavioral Law and Economics (Northampton, MA: Edward Elgar, 2018).

U.S. Centers for Disease Control and Prevention, "Thirty Years of HiV - 19812011," Morbidity and Mortality Weekly Report 60(21) (2011), 689.

U.S. Food and Drug Administration, "Revised Recommendations for Reducing the Risk of Human Immunodeficiency Virus Transmission by Blood and Blood Products: Guidance for Industry," Federal Register 80(246) (2015), 79913-79915.

von Thadden, E.-L. And X. Zhao, "Incentives for Unaware Agents," Review of Economic Studies 77 (2012), 197-222.

__, "Multi-task Agency with Unawareness," Theory and Decision 79 (2014), 1151-1174.

Zamir, E. And D. Teichman, eds., The Oxford Handbook of Behavioral Economics and the Law (New York: Oxford University Press, 2014).

Zhao, X., "Framing Contingencies in Contracts," Mathematical Social Sciences 61 (2011), $31-40$. 